\title{
WHO IS MOST VULNERABLE? EXPLORING JOB VULNERABILITY, SOCIAL DISTANCING AND DEMAND DURING COVID-19
}

Research Article

\author{
Richard Johnston ${ }^{1}$, Ryan Hogg${ }^{1}$ and Kristel Miller ${ }^{2 *}$ \\ 1 Ulster University Economic Policy Centre, Ulster University, Belfast, Northern Ireland. \\ 2 Ulster University Business School, Ulster University, Belfast, Northern Ireland.
}

\begin{abstract}
COVID-19 has resulted in global lockdowns, social distancing and demand fluctuations. Existing crisis management research often provides a retrospective account of strategy making after a crisis. Limited studies have explored the factors which aid policy responses during an ongoing crisis. This research helps fill this gap by exploring the influence Covid-19 had on job vulnerability during the first wave of the COVID-19 crisis (spring and summer of 2020). We explore Northern Ireland (NI) which historically has experienced disadvantages. We utilise point-in-time modelling which considers contextual variations. The findings reveal that a reduction in social distancing reduces the vulnerability of over 30,000 jobs, however, ongoing uncertainties regarding demand will have a more significant longer-term impact on job vulnerabilities. We identify how COVID-19 may impact sectors, groups and geographies differently. We provide policy recommendations on how to alleviate the impact COVID-19 has for job vulnerability across the NI economy.
\end{abstract}

Keywords: Covid-19; Job vulnerability; Social distancing; Demand; Crisis; Policy response

(C) Sciendo

\section{INTRODUCTION}

The COVID-19 health pandemic has caused global economic and social disruption which may exceed prior crises (Clauss et al. 2021; Shankar, 2020; Foss, 2020). Alongside posing a significant risk for individuals health and putting pressure on medical systems, COVID-19 has impacted the movement of people and goods. This has resulted in firms having to repeatedly close due to government lockdowns, enforcement of 'stay at home' and 'work from home' restrictions and social distancing requirements. In the context of Covid-19, social distancing refers to limiting physical contact with others not in your immediate household or 'bubble' and the need to keep physically apart from others when in public. Social distancing has been found to ease transmission during health pandemics (Sharma et al. 2020; Ferrante et al. 2011). However, it will ultimately have a profound economic impact for regions (McKinsey and Company, 2020).

A key consequence of any crisis is the risk of job vulnerability and job insecurity (Ashford et al. 2012; Shoss, 2017). Shoss $(2017,1911)$ identifies that job insecurity represents "a threat to the continuity and stability of employment as it is currently experienced". Bardhan and Tang (2010) refer to vulnerability as the ability of an occupation or job to withstand shocks and quickly bounce back. The impact of any shock on an economy will depend on the degree of vulnerability of sectors and subsectors, which will vary across regions. Job insecurity and risk of unemployment can result in social and political instability and desperation (social exclusion) (Asford et al. 2012). Furthermore, job vulnerability and insecurity has been found to supress household consumption (Benito, 2005; Ganong and Noel, 2015). However, the concept of consumption and demand for particular goods and services could be considered to be differentiated within the context of Covid-19. Consumer demand was not constrained due to wilful consumer behaviours, but demand was influenced by business closure, restricted movement of people and social distancing. 
Existing crisis management research often provides a retrospective account of strategy making after a crisis. Limited studies have explored the factors which can aid policy responses during an ongoing crisis (Aguinis et al. 2021; Wenzel et al. 2020; Williams et al. 2017). Policy makers who implement immediate interventions during a crisis may be more successful at mitigating against job insecurity and ensuring regional economic resilience (Kraus et al. 2021a; Martin and Sunley 2015; Benner, 2012). However, in the absence of real time data, implementing targeted policy interventions can be challenging during a 'dangerously unique' crisis (Borio, 2020) such as Covid-19. This research seeks to achieve the following objective: To explore the influence Covid-19 had on job vulnerability across different occupations and groups during the first wave of the COVID-19 crisis (spring and summer of 2020). Due to regional contextual factors which may influence the impact of a crisis, we focused on the region of Northern Ireland which historically has experienced disadvantages and was one of the hardest hit UK regions in the 2008/09 recession (Magill and McPeake 2016). This paper also explores how policy interventions can alleviate job vulnerability caused by social distancing and reductions in demand. To achieve this, we adapt a methodology used by McKinsey and Company (2020) in order to provide a point-in-time estimate of job vulnerability which considers contextual factors unique to NI. The findings provide a detailed analysis and breakdown of job vulnerability by specific occupations and groups (sectors, age, gender, income groups and regional geographies) and across subregions of $\mathrm{NI}$, which changes when social distancing is reduced from two metres to one metre. The results also provide valuable insights for policy makers illustrating how future job vulnerability and demand will be impacted by further social distancing restrictions. Furthermore, we provide policy recommendations which may help mitigate long term job vulnerability across NI.

\section{Implications of a Crisis for Businesses and Society}

A crisis can be generally defined as an event that has a significant outcome on the function and performance of the future interests of a business (Regester and Larkin, 2002). Crisis management is required in order to return an organisation to "normal function" during or preceding disruption (Breier et al. 2021; Kraus et al. 2020). Past crises such as the 2003 SARS global outbreaks (Goddard et al. 2006), and global recessions (1975, 1982, 1991 and 2009) are exemplars of how government policy and actions are imperative to alleviating the impact on businesses and society as a whole, both in the short and long term. Due to limited real time data, prior research on crisis management often focuses on the aftermath of a crisis, with limited studies focusing on a crisis whilst it is still ongoing (Williams et al. 2017). However, literature does identify that crises often have an impact on employment within regions. Depending on the nature of the shock (e.g. economic, health, natural disaster or technological development), it can result in both job insecurity and job displacement. Job displacement can have long ranging impacts, where highly educated individuals often avail of lower skilled jobs, which leads to the displacement of lower skilled individuals (Gesthuizen and Wolbers, 2010; Kalleberg, 1996). Job switching is an option during times of crisis however, it is reliant upon employees having the necessary transferrable cross sectoral skills. Neal (1998) cautions that workers often build human capital and sector specific knowledge and skills, which will incur high costs to switch to a completely new occupation. Furthermore, prior research identifies the long ranging impact of job losses due to crises, which can last for several decades (Wachter et al. 2020; Papadopoulos, 2016).

It is suggested that crises do not impact all individuals equally, which consequently can lead to higher levels of job insecurity and vulnerability across specific sectors and types of individuals. For example, O'Higgins (2014) and Verick (2009) identify that the 2008 economic recession had a larger impact on sectors such as manufacturing, construction, services and tourism compared to others. Research also suggests that young people across all socioeconomic settings appear to be most impacted by prior recessions (Dietrich, 2013; Papadopoulos, 2016; Arpaia and Curci, 2010). O'Higgins (2014) identify that 40\% of those unemployed in 2009 were individuals between 15 and 24 . Sironi (2018) suggests that unemployment can have a long-term impact on young people, resulting in lower pay and poorer working conditions for those who do manage to find work. Furthermore, it is widely reported that individuals with lower levels of formal qualification have more limited employment stability overall (Cairo and Cajner, 2018) and are more at risk of unemployment (Gebel and Giesecke, 2011). Gebel and Giesecke, (2011) identify that less skilled individuals often have to take on more temporary roles. However, temporary roles are suggested to be the first to lose their jobs during a recession (Peck and Theodore, 2007).

The impact of a crisis on the demand for goods and services is also widely documented within prior literature. Indeed, prior research by Pettigrew et al. (2014) and Ashford and Ashford (2012) suggest that even the threat of 
potential job loss or reduction will negatively influence consumers spend and consumption patterns. Consequently, at times of recessions or other crises where there is job insecurity or vulnerability, demand for particular goods and services may be reduced, further increasing the risk of unemployment within particular sectors (Eugenio Martin and Campos-Soria, 2014; Papatheodorou, Rosselló and Xiao, 2010). However, some authors suggest that switching to part-time working models or placing individuals on short term work schemes, such as those evident in Germany after the 2008 financial crisis, can help alleviate the impact that crises can have on the short term negative demand changes to goods and services (Boeri and Bruecker, 2011). This may limit unemployment. However, this type of strategy is thought to best suit occupations which have high recruitment and firing costs, are reliant upon specialised human capital and are in countries with strong employment legislation (Lydon et al. 2019).

Unemployment and demand reduction can have severe negative consequences to society and regions overall. McGann (2020) identify that it took many regions over a decade to return to pre-2008 economic recession employment rates and caution that the number of workers which will be displaced by COVID-19 is potentially much higher. Consequently, a timely and effective government and policy response is imperative to mitigate the potential short and long-term impacts of Covid-19. Prior research has resulted in mixed findings on whether centralised or decentralised governance structures will result in more positive effects (Schatz and Berlin, 2011; Jiang et al., 2020). These mixed findings could be explained by the variations in context and magnitudes of a crisis; which make decision making and indeed policy making inherently difficult. During a health pandemic, policy makers are faced with difficult competing values relating to protecting the health and well-being of society versus limiting the impact on the economy (Sharma et al. 2021). Drawing on the public value literature, it can be derived that policy makers have a duty and are accountable for decision making. Their laws, regulations, services and other actions should create value for society (Faulkner and Kaufman, 2017). This becomes difficult during a health crisis, where paradoxical and competing values arise (Yang, 2020). Protecting health at the expense of the economy are ultimately intertwined, where an economic downturn may increase job vulnerability, which in turn can lead to unemployment and negative healthcare outcomes. Rising unemployment in turn has a negative impact upon consumers purchasing power which in turn will limit economic recovery (Ashford et al. 2012; Sharma et al. 2021; Sheth, 2020).

In the case of Covid-19, the initial speed of action by governments varied across the globe due to issues associated with the collation of data on the impact and spread of the virus. By the middle of March 2020, many countries had enforced strict measures to reduce travel within and amongst countries, established social distancing regulations, required businesses to cease trading temporarily or move operations online (UK Government 2020). This has had a considerable impact on economies globally where stock markets slumped by as much as $35 \%$ in March 2020 and unemployment levels increased globally by between $3.8 \%$ and $12.7 \%$ (IMF, 2020). The enforcement of social distancing is a novel and unique characteristic of the COVID-19 policy response, which differs from prior crises, which makes it difficult to use predictive modelling and forecasts (Panovska-Griffiths, 2020). Furthermore, policy decision making in a crisis is also compounded by an unavoidable time-lag between the crisis onset and the publication of data on real time impacts. This demands innovative approaches and analytical insights which combines expert knowledge and cognitive and normative frames (Surel, 2000; Schiliro, 2013). Following McKinsey and Company (2020) we argue that point-in-time estimates at a regional level may be useful to analytically explore the potential impact of a crisis on job vulnerability. This will provide data which can inform immediate policy responses to alleviate the impact of a crisis.

\section{The case of Northern Ireland (NI)}

This research is focused on NI which is a peripheral region of the UK and shares a land border with the Republic of Ireland. Historically, the region has experienced social and economic challenges (Rowthorn, 1981; Birnie et al. 2019). Some of these are attributed to political conflict which started back in the 1960s, referred to as 'The Troubles'. This political conflict resulted in an increase in unemployment which was compounded by a declining manufacturing sector (PWC, 2016). As a post conflict society, it has made significant progress however, it is still one of the most disadvantaged regions of the UK (HM Treasury, 2011; PWC, 2016). NI was one of the hardest hit UK regions in the 2008/09 recession, where the economy contracted by $7.8 \%$ (Magill and McPeake 2016). Whilst the economy has been slowly recovering, it has not yet reached 2008 pre-recession levels (PWC, 2016) and still remains dependent on a large public sector, where a large proportion of the private sector is lower, value-added business activity in the non-tradable sector (Teague, 2016). Furthermore during 2019, NI was ranked as the least innovative region in the UK (BEIS, UK Innovation Survey, 2019) which is a position it had maintained for most of the last decade. This signals the ongoing challenges the region is facing in improving productivity and economic growth. Pre-COVID-19, 
the region has also been faced with economic uncertainties relating to Brexit, where it is predicted that it will be the most negatively impacted UK region. A hard border could undermine the Good Friday Agreement and the 1998 NI Act (European Parliament Briefing, 2018). Considering the historical and unique contextual factors surrounding $\mathrm{NI}$, it could be suggested that COVID-19 will severely impact the region, and result in an economic contraction far greater than the 2008/09 recession. Consequently, there is a need for creative modelling to aid understanding of potential impacts of Covid-19 in order to develop an appropriate policy response.

\section{METHOD AND DATA}

The diffusion of COVID-19 in early 2020 was marked by the immediate shutdown of large parts of the economy. We suggest that it is appropriate and useful to analyse the labour market at the point of impact; assessing where those impacts would be most likely to be seen. A point-in-time analyses can be a powerful tool to provide robust insights in real time during a particular situation or event (McKinsey and Company, 2020). In contrast, a time series analysis requires comparator historical events and therefore was not available to help inform decisions relating to Covid-19. Point-in-time analyses act as a barometer of change and as a signposting mechanism for policymakers, highlighting vulnerabilities at a particular point-in-time (Klein et al. 2007). It can be completed as a one-off analysis, as a reactive tool for policymakers to aid decision-making in lieu of official data (McKinsey and Company, 2020). However, it can be completed again in the future as updated data becomes available. In order to achieve the research question, a baseline vulnerability model was created as a strategic tool which could be adjusted for changes in both public health and economic circumstances.

The unique circumstances of COVID-19 suggests that its impacts may vary based on the characteristics of both an industry and a job. For example, an online-based business may not be impacted as much as a customer facing businesses. We suggest that the context of COVID-19 necessitates an earlier identification of job vulnerability compared to other crises, for example during the recession of 2008/09. Accordingly, a point-in-time analysis is of value for policymakers to identify vulnerabilities early and dedicate resources to mitigate income and output loss among specific groups in the short term, and to prevent economic scarring and industrial decline in the long term.

The baseline model and method used in this study was adapted from the model created by McKinsey and Company (2020) at the outset of the crisis, which attempted to understand the implications of COVID-19 for US workers. However, the context and specific nature of $\mathrm{NI}$ demands adaptations to their model and will allow for context specific regional insights to be gained. Figure 1 provides an overview of the methodology implemented in identifying job vulnerability in NI. Each of the data collection stages will now be discussed.

Figure 1: Data Collection Process

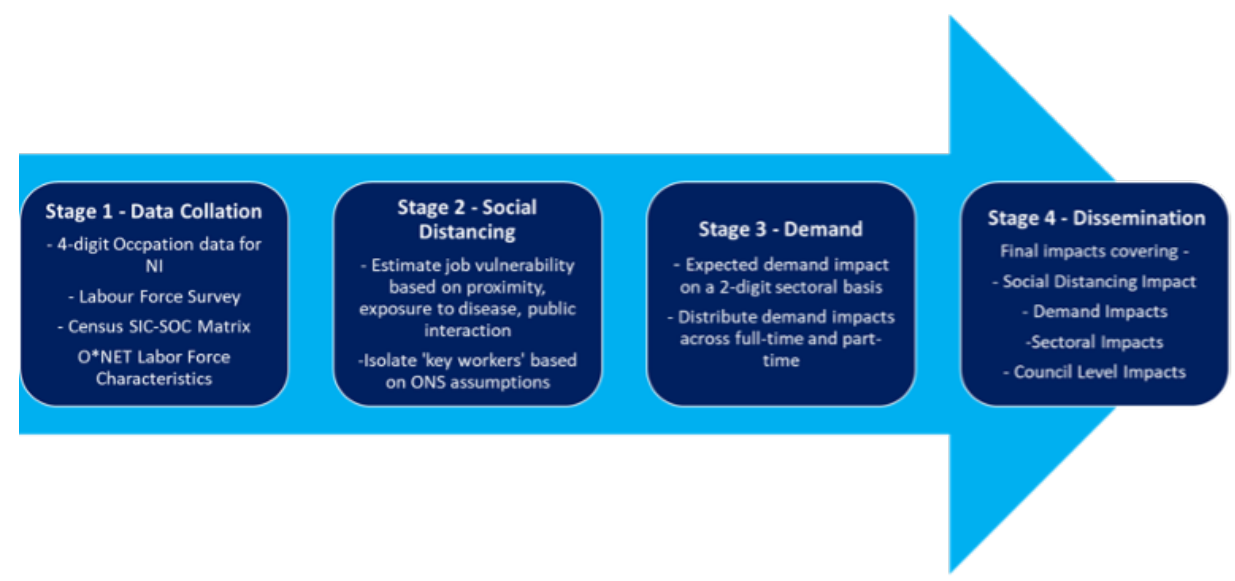

\section{Stage 1 - Data Collation}

A variety of data sources were used to inform the assumptions which took into account Nl's characteristics. First, the UK, Office for National Statistics' Labour Force Survey (LFS) occupational data was used to create a 'pre-COVID' 
labour market outlook for NI (ONS, 2019). This was developed by averaging the four quarters of the LFS in 2019. Other data sources deployed were data from the Department for Labour O*NET Occupational Characteristics (Onet, 2020) which provided an indexation for relevant characteristics; the NI Economic Forecasting Model $^{1}$ from Ulster University Economic Policy Centre (UUEPC), which provided a baseline sectoral structure for the NI economy; LFS occupational data (by full-time and part-time classification), Annual Survey of Hours and Earnings (ASHE) wage by occupation data (ONS, 2019b) and LFS qualifications by occupations data, which was used for disaggregation of vulnerable demographics. Table 1 provides a summary of the various data which was used to model job vulnerability in NI.

Table 1: Methodological approach to estimating labour market vulnerability in NI

\begin{tabular}{|c|c|c|c|}
\hline Section & $\begin{array}{c}\text { Baseline Occupational } \\
\text { Data }\end{array}$ & Social Distancing impacts & Demand-side impacts \\
\hline Data collection & $\begin{array}{c}\text { - US Department of Labor } \\
\text { O*NET Occupations data } \\
\text { - ONS LFS } 4 \text {-digit Occupational } \\
\text { Data } \\
\text {-ONS SIC-SOC Matrix }\end{array}$ & $\begin{array}{l}\text { - US Department for Labor O*NET } \\
\text { Occupational characteristics } \\
\quad \text { - ONS BICS } \\
\text { - ONS Essential workers analysis }\end{array}$ & $\begin{array}{c}\text { - McKinsey \& Co. industrial analysis of } \\
\text { demand-side impacts } \\
\text { - OBR2 Coronavirus Reference Scenario GVA } \\
\text { Forecasts } \\
\text { - ONS BICS } \\
\text { - Ulster University Economic Forecasting } \\
\text { Model } \\
\text { - Ulster University Economic Policy Centre } \\
\text { Labour market assessments (Magill \& } \\
\text { McPeake, 2020) }\end{array}$ \\
\hline $\begin{array}{l}\text { Method for } \\
\text { analysis }\end{array}$ & $\begin{array}{c}\text { - Creation of a baseline labour } \\
\text { market model } \\
\text { - Aggregating } 360 \text { UK sub- } \\
\text { occupations to } 11 \text { major } \\
\text { occupational groups } \\
\text { - Disaggregation on the basis of } \\
\text { male, female, part-time, full-time, } \\
\text { at the 3-digit level } \\
\text { - Disaggregation on the basis of } \\
\text { qualifications, wages at 2-digit } \\
\text { level }\end{array}$ & $\begin{array}{l}\text { - US Occupations transposed to UK } \\
\text { Occupations using ONS reclassification } \\
\text { - Standardised score out of } 100, \\
\text { taking weighted average of 'proximity', } \\
\text { 'exposure to disease' and 'working with } \\
\text { others' scores } \\
\text { - Score }<55=\text { 'low risk' } \\
\text { Score }=>55=<65=\text { 'medium risk' } \\
\text { Score }>65=\text { 'high risk' }\end{array}$ & $\begin{array}{l}\text { - Standardised demand-side impacts applied } \\
\text { to 2-digit sectors in NI } \\
\text { - Impacts filtered through SIC-SOC matrix to } \\
\text { determine impact across occupations } \\
\text { - Filtered across demographics including } \\
\text { gender, age and levels of formal qualification }\end{array}$ \\
\hline Results & & $\begin{array}{l}\text { - Measured as share of workers in } \\
\text { an occupation vulnerable to social- } \\
\text { distancing. Impact was reported } \\
\text { according to high, medium and low risk }\end{array}$ & $\begin{array}{l}\text { - Measured as a share of workers in an } \\
\text { occupation vulnerable to demand-side } \\
\text { impacts, based on sectoral forecasts }\end{array}$ \\
\hline
\end{tabular}

\section{Stage 2 - Social Distancing}

In line with the methodology followed by McKinsey and Company (2020), this study utilised Department of Labor O*NET (2021) occupational characteristics data to estimate the vulnerability of all 967 US occupations ${ }^{3}$ to social distancing measures. We applied the US occupations to the UK's Standard Occupational Classification framework, on a best fit basis, to utilise the 369 4-digit occupations available for NI. This was done using a conversion matrix developed by the Office for National Statistics (ONS, 2021a). The key data included were proximity to others in the workplace, level of interaction with the public, and potential of exposure to the COVID-19 virus (McKinsey and Company, 2020). This data was ranked on a scale of 0-100. Estimates of proximity, interaction and probability of exposure were based on US focussed research (Peterson et al. 1997), and transposed onto UK occupations. This was done with the assumption that these occupational characteristics do not vary significantly between two developed economies like the UK and the US. Occupations were also classified into 'Essential' and 'Non-essential'

1 An internal forecasting model used by UUEPC informing sectoral trends.

2 Office for Budget Responsibility (2020), which produces outlooks for the UK Economy. In March 2020, they released a 'Coronavirus Reference Scenario' which forecasted GDP losses across the UK sectors.

3 These are the standard occupational classifications used by the United States Department of Labor and are comparable with UK standard occupational classifications (ONS, 2021a). 
based on further classification by the ONS (2021a). The outcome of these vulnerabilities allowed a categorisation of occupations on the basis of 'low', 'medium' and 'high' levels of risk, dependent upon 2 metre and 1 metre social distancing regulations that were in place at different points in time. This follows the categorisations utilised by McKinsey and Company (2020).

Determination of vulnerability levels were based on a weighted average of scores from 'proximity', 'exposure to disease', and 'working with the public'. Greater weighting was given to 'exposure to disease' and 'working with the public'. A statistical adjustment was made to control for high scores across most occupations for 'proximity'. If this was left unadjusted, it would have overemphasised levels of vulnerability in the labour market. Occupations with a standardised score below 55/100 were categorised as 'low' risk; occupations with a standardised score between $55 / 100$ and 65/100 were categorised as 'medium' risk; and occupations with a standardised score higher than $65 / 100$ were categorised as 'high' risk. Table 2 shows the results of this analysis. At 2 metres of social distancing, $10 \%$ of occupations with a 'low risk' score are categorised as vulnerable, compared to $40 \%$ of occupations deemed at 'medium risk' being vulnerable, and $90 \%$ of occupations at 'high risk' were vulnerable. These numbers were then recalculated to apply a reduction from 2 metre to 1 metre social distancing regulations. Assumptions of reduced vulnerability were based on both survey data (ONS, 2021b) and evidence from industry figures, including those in hospitality and retail (McKinsey and Company, 2020; NI Chamber of Commerce, 2020). Vulnerability classifications can be found in Annex 1.

Table 2: Social Distancing Workforce Impact

Share of Workforce Impacted

\begin{tabular}{cccc}
\hline \hline Distance & Low risk & Medium risk & High risk \\
& $10 \%$ & $40 \%$ & $90 \%$ \\
2-metres & $10 \%$ & $30 \%$ & $60 \%$ \\
1-metre & & & \\
\hline
\end{tabular}

\section{Stage 3 - Demand}

The impacts of social distancing were then inserted into the 'baseline' model to create a new social distancing baseline, before considering impacts on demand. Impacts on demand were considered to occur as a second-stage effect, where social distancing requirements materially constrain demand. This is evidenced in the hospitality, retail and recreation sectors where reduced capacity will reduce demand. Furthermore, wider economic factors were considered, which considered that there could be a reduction in household incomes due to restricted trading. Furthermore, it was acknowledged that expenditure levels may be lower due to reduced confidence in the economy (Bank of England, 2020). In this sense, demand can be classified as both consumer demand and labour demand, both of which are likely to be adversely affected by the COVID-19 crisis.

The calculation of these demand impacts were again influenced by McKinsey and Company (2020) who assessed demand on a sectoral basis. This had to be adjusted for NI using emerging evidence from surveys (ONS, 2021b), UK sectoral Gross Value-Added forecasts (OBR, 2020), local forecasts and labour market insights (Magill and McPeake, 2020). Demand impacts were also adjusted based the breakdown of an occupation into part-time or full-time; where it is identified in prior research that part-time work is typically more insecure than full-time work. A central, or most likely scenario provided the baseline, and the upper and lower bounds were provided to illustrate the most likely optimistic and pessimistic outcomes. Demand-side impacts were presented as 'shares of jobs in each sector that are vulnerable'. The baseline demand impacts (based on a central scenario), are detailed in Annex 2. This accounts for demand losses at 1 metre and 2 metre social distancing, and whether the job is carried out on a part-time or full-time basis.

Demand impacts were inserted into a Standard Occupational Code: Standard Industrial Code (SOC: SIC) matrix, which identifies a 4-digit occupation's employment share in each 2-digit sector of NI. This data was from the 2011 Census for NI (NISRA, 2011) and was used as a best estimate for employment structures, in the absence of 
a more recent census. This is regarded as a secure assumption. Structural industrial change has occurred in the last decade, however the types of occupations carrying out work within sectors are not expected to have changed to the same extent. This modelling allows vulnerability of an occupation to social distancing requirements, and to demand impacts to be identified.

Demand-side vulnerability was calculated for the remainder of jobs across occupations that were not affected by social distancing. This allowed a demand-side vulnerability figure for each occupation. When this was aggregated with social distancing vulnerabilities, it presented an estimate of total vulnerability across occupations. Social distancing and demand impacts were modelled at a social distancing requirement of 2 metres and then at a 1 metre requirement.

\section{Stage 4 - Dissemination}

The model outputs are reported on an occupational, sectoral, part-time and full time, geographical, gender, income and qualifications basis. This was achieved using Labour Force Survey baseline evidence and the Office of Budget Responsibility analysis of Coronavirus Job Retention Scheme (CJRS) claimants (OBR, 2020). Other comparisons, including ethnicity and religious background were not possible due to a lack of granular occupational data in NI.

\section{FINDINGS}

The findings provide a point-in-time estimate of job vulnerability during the first wave of the COVID-19 crisis during Spring and Summer of 2020. It was found that between $240,000-280,000$ jobs were vulnerable between April and June of 2020 under the 2-metre social distancing rule. It was found that a reduction to a social distancing requirement of 1 metre caused a 12\% drop in vulnerability, helping to reduce vulnerability by an additional estimated 30,000 jobs. This is primarily a result of capacity improvements in customer-facing occupations, which resulted in a positive demand-side effect. However, our research indicates that a reduction in consumer demand is the primary factor relating to job vulnerability and is suggested to remain so for the remainder of the crisis and beyond. It was found that between $58 \%-63 \%$ of jobs are vulnerable as a result of tangential and second-stage demand impacts. A reduction in demand is more difficult to resolve economically than the relaxation or removal of social distancing rules. The next section explores these findings further and analyses job vulnerability in terms of its demography and composition.

\section{Relationship between social distancing and demand reductions}

The most significant policy developments in the UK to help alleviate job vulnerability were those of the Coronavirus Job Retention Scheme (CJRS), Self-Employment Income Support Scheme (SEISS) and rates relief from the NI Executive for $\mathrm{NI}$ businesses. Social distancing measures were relaxed from a minimum distance of two-metres to one-metre on $29^{\text {th }}$ June 2020. Based on our occupational vulnerability model, it was estimated that this change reduced the number of vulnerable jobs from 260,000 to $230,000(-12 \%)$. While a pre-COVID estimate was unavailable due to lack of data, 230,000 jobs being vulnerable is suggested to be much higher than 'normal' times. As such, it could be derived that there was a greater risk of unemployment due to social distancing requirements constricting activity in a significant proportion of the labour market. This has implications for several sectors, both from a labour and customer perspective. In production or customer facing sectors, halving of the two-metre social distancing rule increased the number of people that can work on a factory floor, shop or office, which targets those deemed as non-essential workers. This change then provides a reduction in CJRS support requirements and a boost to output (or GVA). In retail and hospitality, loosening of social distancing provided a dual benefit in terms of mitigating the labour market impact, as well as the ability to boost capacity within the retail and hospitality sectors. This should then improve the potential for these places to generate demand and revenues that are closer to prepandemic levels. Figure 2 shows the impact social distancing requirements had on the job vulnerability of certain occupations. 
Figure 2: Vulnerable jobs by occupation, two metre and one metre social distancing requirements: Top ten occupations, NI, June 2020

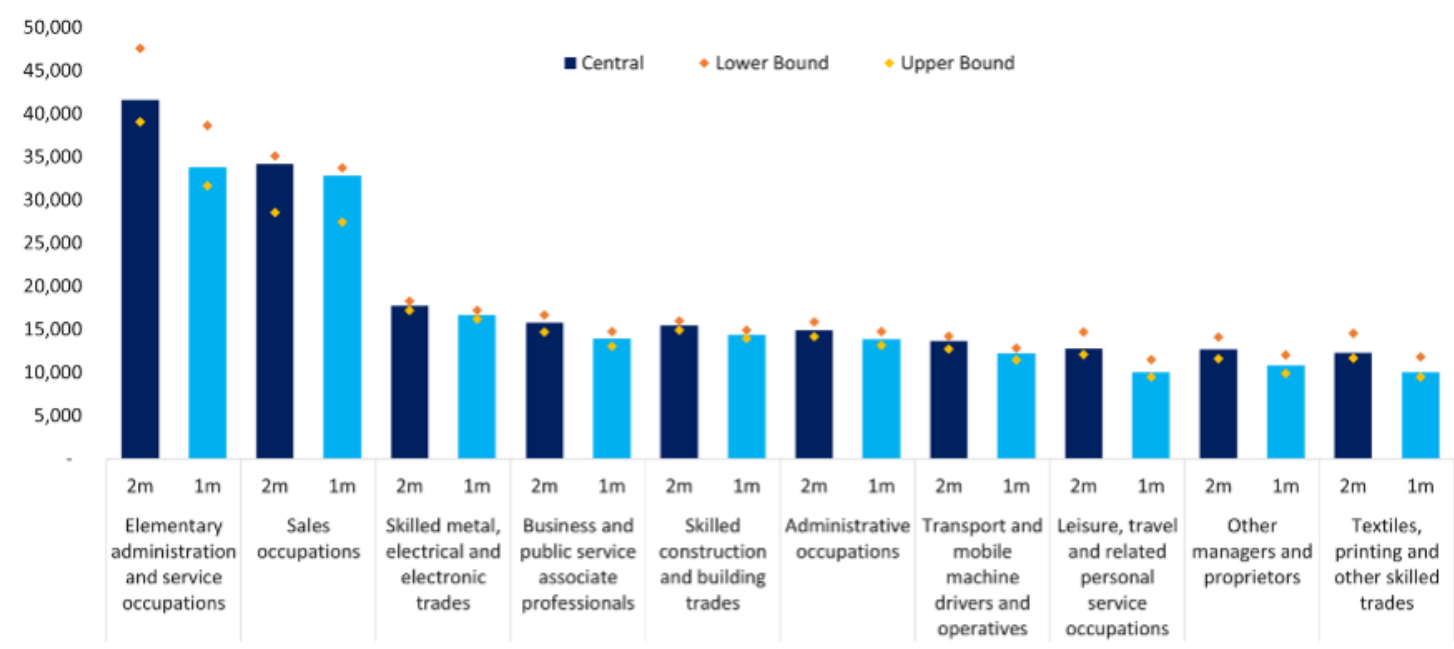

Note: Figure 2 illustrates vulnerability reduction from 260,000 to 230,000 jobs including both social distancing and demand reductions

Figures 2, 3 and 4 show that the largest relative impacts were expected to occur in occupations such as leisure, travel and related personal services. It was found that up to one in five posts would no longer be considered vulnerable with a reduction in social distancing to 1-metre. This is equivalent to approximately 3,000 jobs overall and approximately 2,500 jobs within sectors such as textiles, printing and other skilled trades. The reduction in social distancing could also remove about one fifth of the workforce from vulnerability.

The vulnerability reductions are a transposition of the occupational trends using the SOC: SIC matrix. Those working in hospitality and sales occupations were more heavily represented in the accommodation and food, and wholesale and retail sectors respectively. At the last census in 2011, elementary administration and services occupations made up $44 \%$ of all jobs in the accommodation and food and wholesale and retail sectors. While social distancing measures disproportionately impacted these sectors at the outset, they would be expected to see the most significant gains from social distancing relaxations.

Figure 3: Vulnerable jobs by sector, two metre and one metre social distancing requirements: Top ten sectors, NI, June 2020

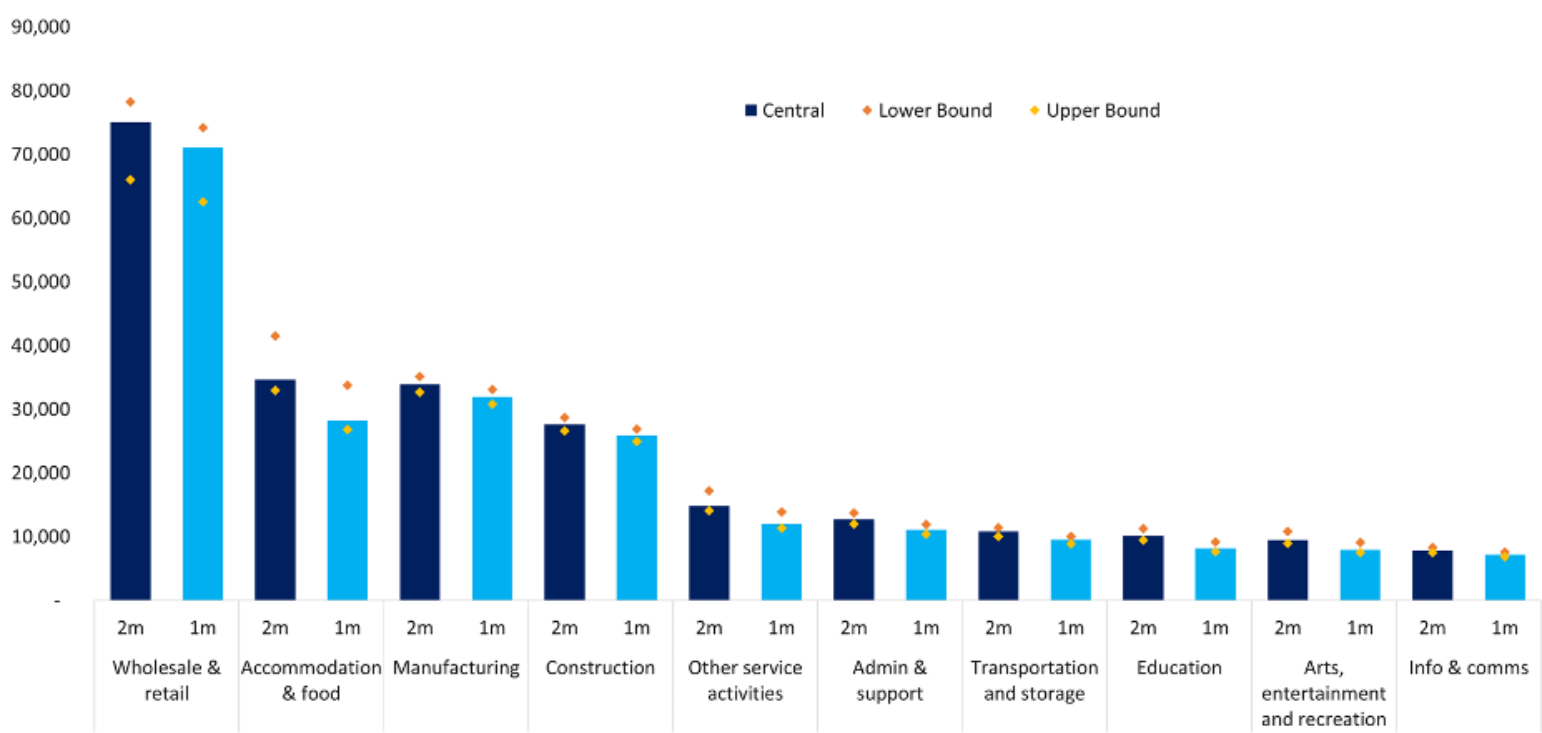


Figure 4: Reduction in job vulnerabilities as a result of reducing social distancing requirements from 2-metre to 1-metre: Top ten occupations, June 2020, NI.

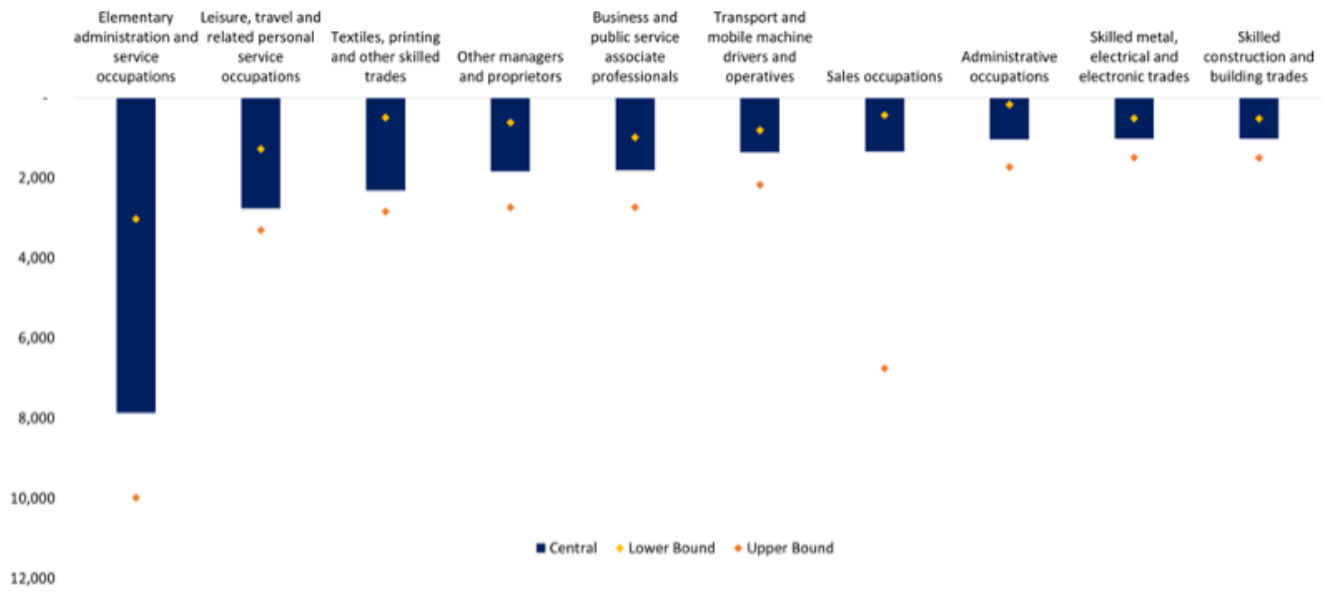

Please note that figure 4 illustrates vulnerability reduction from 260,000 to 230,000 jobs when including both social distancing and demand reductions.

Figure 5 shows that accommodation and food services, which had approximately $59 \%$ of employee jobs being supported via the CJRS across the $\mathrm{UK}^{4}$ in June 2020, was the sector who would benefit the most from a reduction in social distancing. It was found that $10 \%-30 \%$ of these jobs would no longer be classed as vulnerable under a 1 -metre rule. Wholesale and retail would account for $10 \%-23 \%$ of jobs that would be no longer classed as vulnerable and other services would account for a further $8 \%-10 \%$.

Figure 5: Reduction in job vulnerabilities as a result of reducing social distancing requirements from 2-metre to 1-metre: Top ten sectors, $\mathrm{NI}$, June 2020

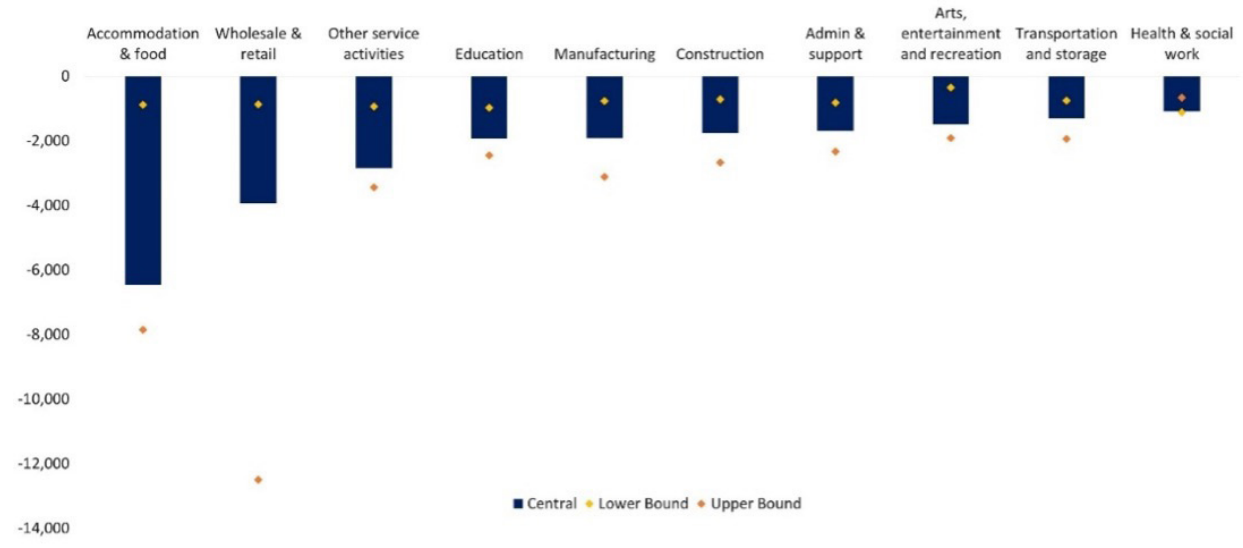

It could be suggested that there is a relative logistical flexibility for most firms in responding to the social distancing rule. Many jobs can be carried out at home, while others can be continued at a distance. The modelling suggests that the most vulnerable are highly exposed to job loss, however, they ultimately make up a minority of the workforce. The greatest risk to the economy does appear to result from demand constriction, where issues with demand will likely continue in certain industries such as hospitality and leisure until social distancing measures relax completely. Slowing economic activity has structural impacts on the economy, which will hurt consumer confidence and lead to a collective tightening in discretionary spending. This 'paradox of thrift' (Keynes et al. 2018) across society could prove much more damage to the economy and labour market in the long term.

4 Statistics obtained from the HMRC, 2020 
From our analysis, it was identified that demand reductions for goods and services from consumers, and for labour from employers, would be the most significant driving factor of vulnerability (almost two thirds: one third ratio of demand to social distancing). However, patterns differ by occupation and sector. This is illustrated by the 90:10 relationship in sales occupations and retail and wholesale; and by a 20:80 relationship in leisure and travel. This illustrates how individual sectors will be influenced differently by demand stimulating or social distancing policy (retail and hospitality respectively). Our modelling illustrates clearly that retail and wholesale accounts for the largest numbers of vulnerable jobs. However, whilst social distancing relaxations will be welcomed, as mentioned, demand is much more important and therefore is the key risk. As such, other supports may be necessary for those occupations and sectors that are less sensitive to changes in social distancing requirements, and also for those workers that are not returned from furlough.

Figure 6 demonstrates that a very vulnerable occupation, elementary administration and services, is impacted by social distancing requirements. It was identified that those within this occupational group for example bar staff, working in customer-facing, high capacity roles had $67 \%$ job vulnerability at the 2 -metre social distancing restriction, and $62 \%$ at the 1 -metre social distancing restriction. Conversely, sales occupations, which are heavily exposed to peripheral demand impacts, were found to have $88 \%$ job vulnerability at the height of the crisis.

Figure 7 shows occupational vulnerability and suggests that up to $85 \%$ of wholesale and retail trade jobs are likely to be vulnerable to demand impacts. This is likely to be driven by limited capacity and expected falls in discretionary spending and consumer confidence.

Figure 6: Top 10 vulnerable occupations by impact at 1-metre and 2-metre social distancing, June 2020, NI

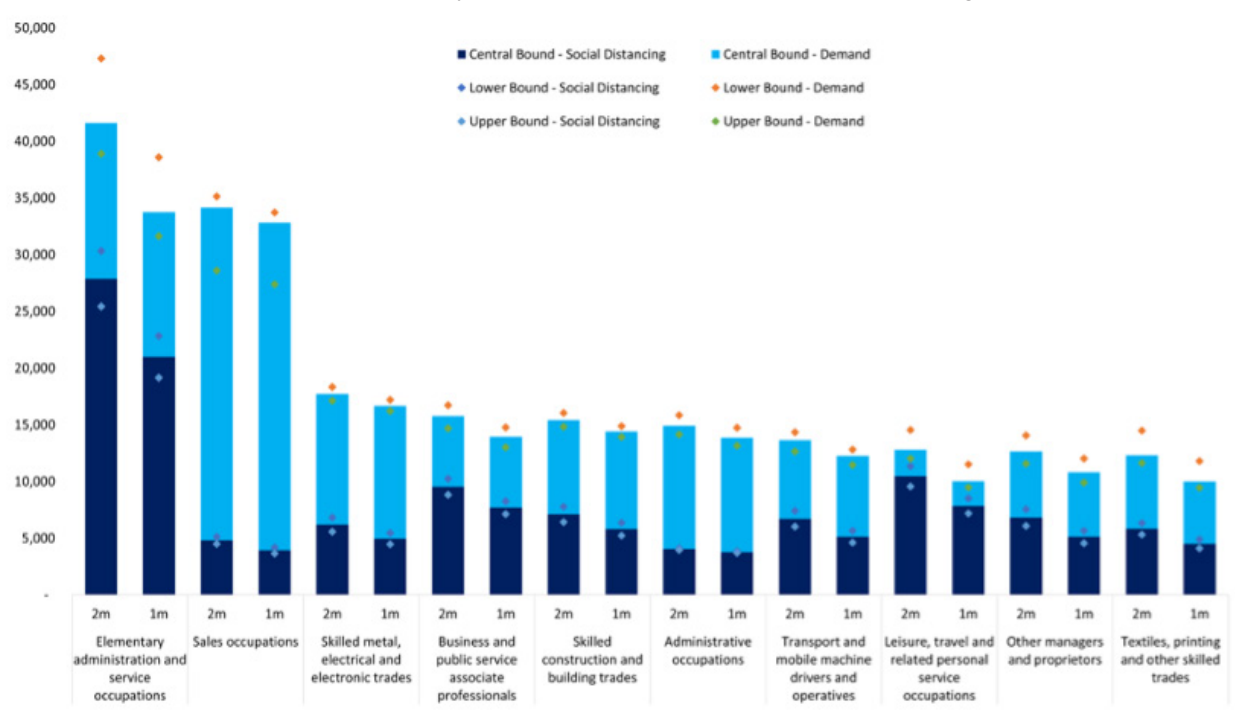

\section{Job vulnerability of specific groups}

Between March and May 2020, there was a strong rise in the number of people not employed in their previously "normal" roles. This took the form of unemployment $\left(64,000\right.$ at time of analysis in May 2020) ${ }^{5}$ or registering on the CJRS which was supporting $80 \%$ of the salaries of up to 212,000 employees in $\mathrm{NI}$ at the beginning of the pandemic. Accounting for those already receiving out of work benefits, that means that 246,000 people not employed in what were previously "normal" forms in NI between March and May 2020. Identifying how and why jobs might have become vulnerable in specific occupations is necessary to understand the likelihood of persistence, probability of recovery and in turn, inform the appropriate policy response. At the outset of the COVID-19 crisis, it quickly became apparent that the impacts were unequal across society in NI. Our point-in-time analysis illustrate that the differentials are evident in terms of part-time/full-time workers, gender, geography, qualifications, income and age. Those in the most at risk occupations and sectors are generally younger, have lower levels of formal qualification and below average earnings, are more likely to be in part-time work and are more likely to be male. This will now be discussed.

5 NISRA, 2020, available at: https://www.nisra.gov.uk/publications/claimant-count-tables 
Figure 7: Top 10 vulnerable sectors by impact at 1-metre and 2-metre social distancing, June 2020, NI

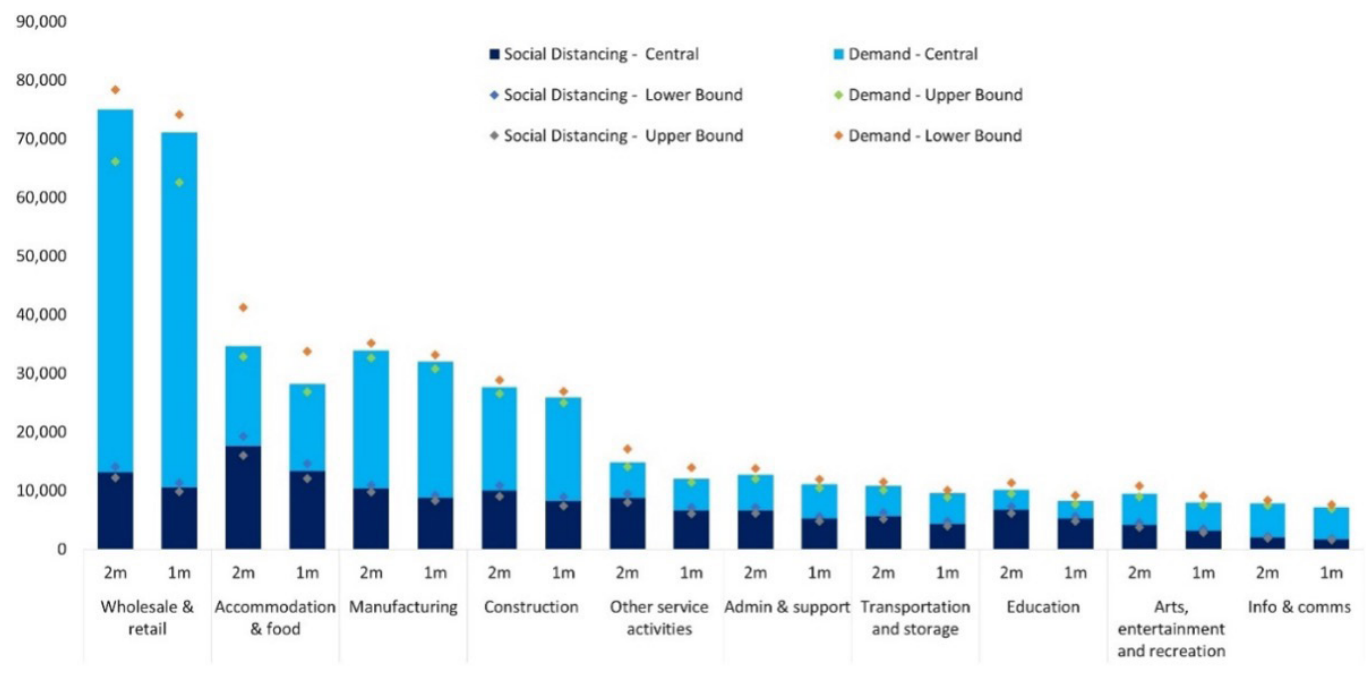

\section{Level of formal qualifications and Covid-19 vulnerability}

Those individuals who have lower levels of formal qualifications are estimated to be the most negatively impacted group in society. They are more likely to be in occupations that have been supported through the CJRS or have become unemployed or economically inactive. In addition, the qualification levels of those who are already economically inactive or unemployed are skewed towards those with lower educational attainment on average (Magill and McPeak, 2016). As shown in figure 8, those with lower levels of formal qualification were likely to find it more difficult to secure employment prior to the COVID-19 crisis (ONS, 2017) and if employed, are more likely to have been in vulnerable occupations and sectors as the crisis unfolded.

Figure 8: Job vulnerability by qualification level

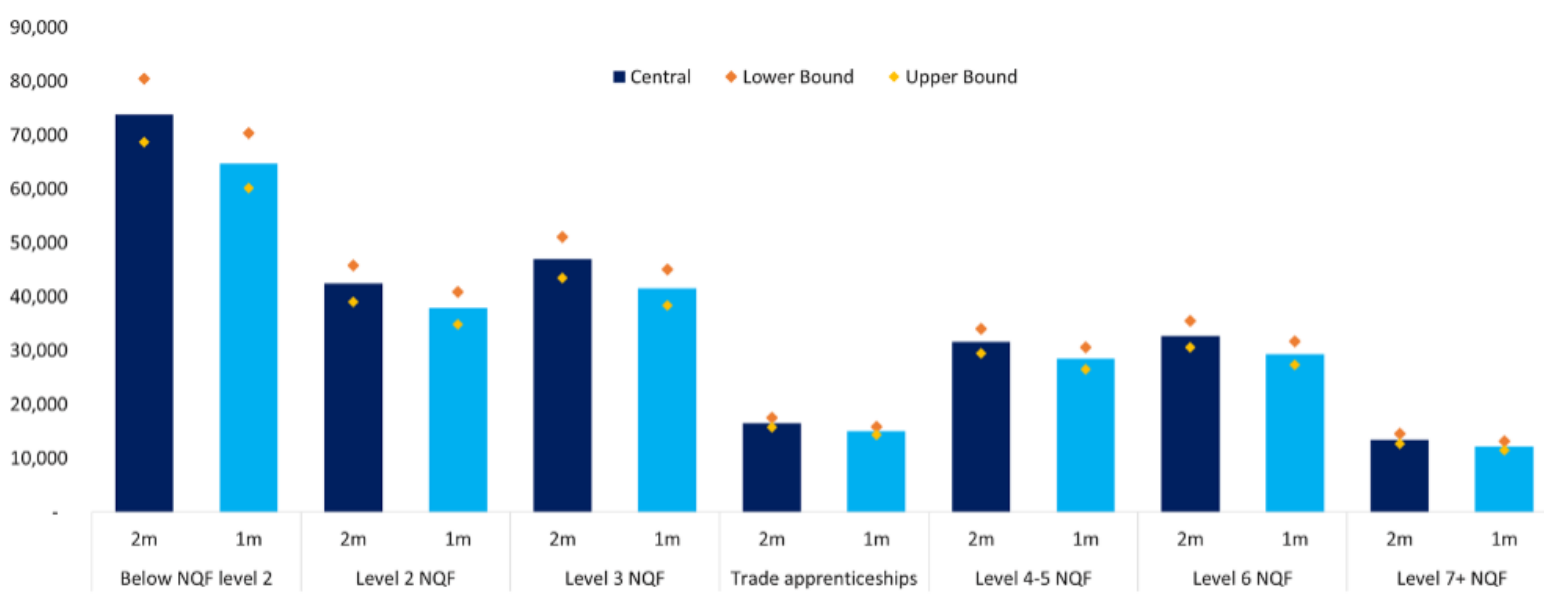

Due to those with lower levels of qualifications being disproportionately impacted by social distancing requirements, it is unsurprising that they are likely to realise the largest relative reduction in employment vulnerability by reducing the 2-metre social distancing rule to 1-metre (see figure 9). Occupations that would benefit from this include;

- Elementary administration and services sector (47\% of workers possess less than level 2 qualifications under the NQF);

- Textiles and printing (43\% of workers possess less than level 2 qualifications); and

- Leisure and travel (39\% of workers possess less than level 2 qualifications). 
Collectively, these occupations account for the removal of approximately 13,000 jobs from vulnerability as a result of the reduction in social distancing. Whilst these lower qualified workers are likely to have other skills (for example experience and aptitudes not captured by a formal qualification), this can be difficult to track formally in a job application process and in related data. Consequently, this increases the risk that those with lower levels of formal qualifications may find it difficult to secure employment as policy supports unwind.

Figure 9: Reduction in job vulnerability by share of qualifications below level 2 NQF, central scenario

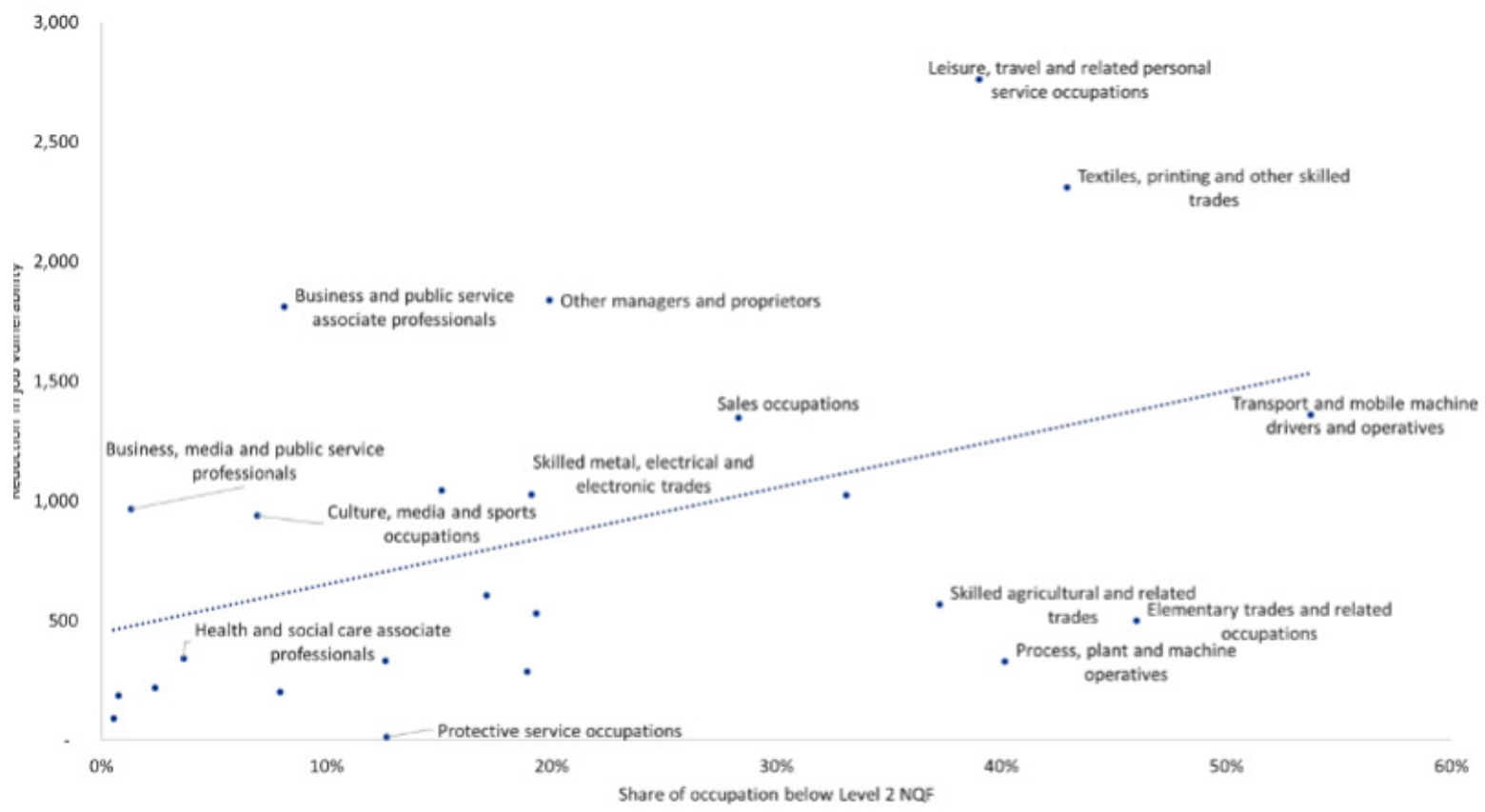

\section{Employee age and Covid-19 vulnerability}

In terms of age groups, it is estimated that $32-38 \%$ of $16-24$-year-old workers were vulnerable to the impacts of COVID-19 in June 2020, compared to 22-26\% of 35 - 44-year-olds, who are the least affected age band (see figure 10). Official data indicates that $29 \%$ of elementary administration and services occupations are carried out by 16-24-year-olds, while one-in-three people working in sales are in this age band (ONS, 2020). Social distancing relaxations to 1 - metre would most benefit the 16-24-year-old age group by removing $2-8 \%$ or $2,000-8,000$ individuals from vulnerability.

Figure 10: Job vulnerability by age band

\section{$45 \%$}

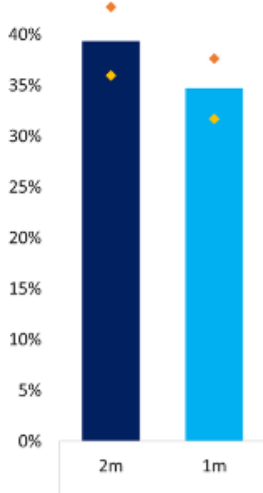

$16-24$
$2 \mathrm{~m}$

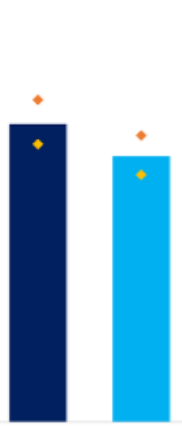

$1 \mathrm{~m}$

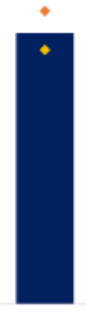

$2 \mathrm{~m}$ - Central - Lower Bound - Upper Bound

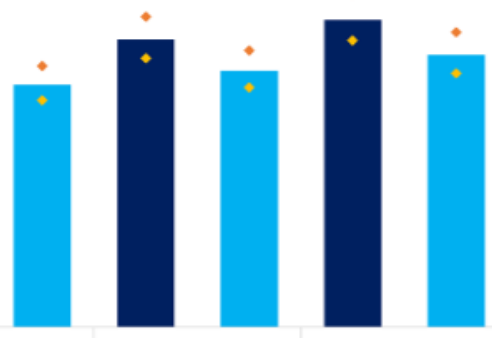

$1 \mathrm{~m}$
$2 \mathrm{~m}$
$2 \mathrm{~m}$ 45. 54 $55-64$

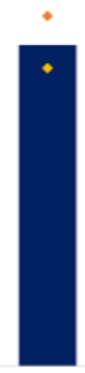

$2 \mathrm{~m}$

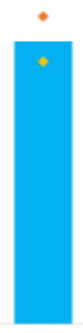

$1 \mathrm{~m}$ 
Figure 11: Vulnerable jobs by salary band: 1-metre and 2-metre social distancing requirements

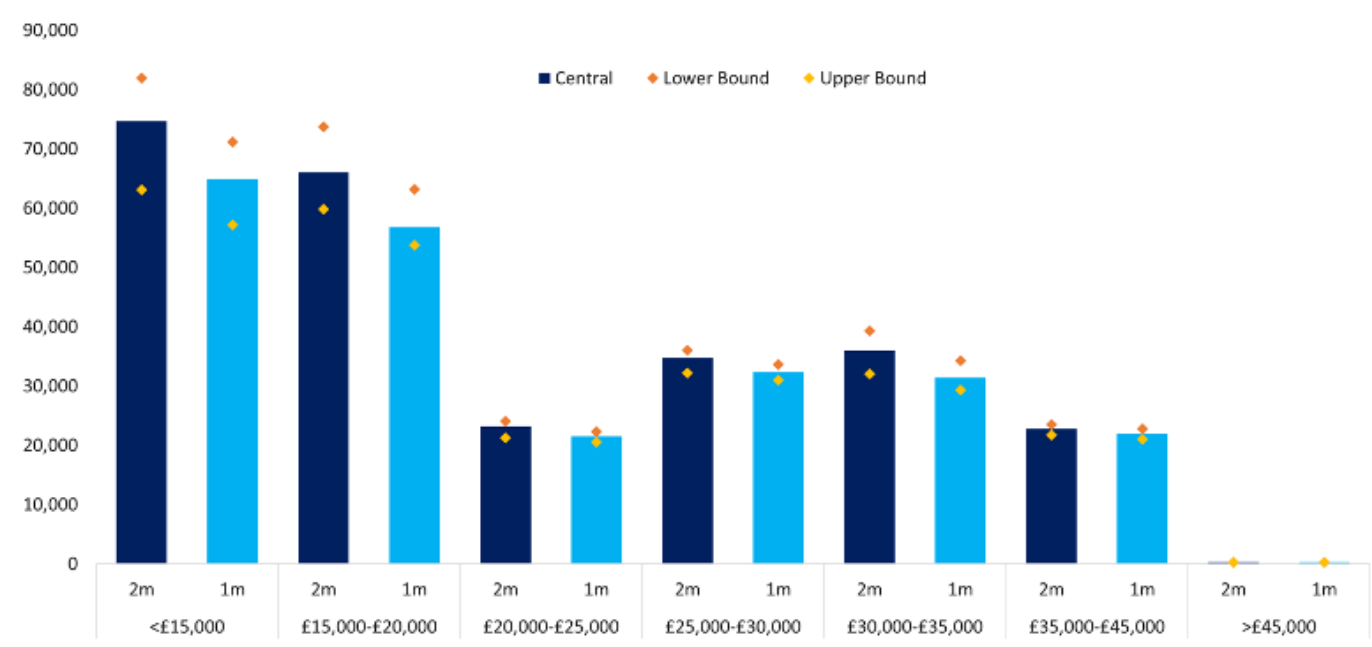

\section{Income groups and Covid-19 vulnerability}

Higher levels of formal qualifications and average earning power are negatively correlated to job vulnerability. The modelling suggested that the lowest earners are disproportionately impacted by job vulnerabilities and are most likely to become less vulnerable due to the reduction in social distancing requirements. Around two thirds of the jobs that are no longer estimated to be vulnerable due to a reduction in social distancing requirements are in occupations in which the median wage is less than $£ 20,000$ (see figure 11).

\section{Gender and Covid-19 vulnerability}

From the point-in-time estimate, figures 12 and 13 indicate that males would be more likely to suffer the negative economic impacts of COVID. 29-33\% of male-occupied jobs are suggested to be vulnerable, compared to 20$25 \%$ of female occupied jobs. Recent increases in health worker demand, which is generally female dominated, has helped ease the impact for females. However, conversely, male dominated sectors such as manufacturing and construction are some of the early returners from CJRS. Interestingly, when the impact of social distancing relaxations are considered, females are slightly more likely to be removed from vulnerability than males. $5 \%-20 \%$ of female held jobs are likely to see vulnerability reduce, compared to $5-15 \%$ for male held jobs. This is a product of the two occupations that benefit most from the reduction in social distancing (elementary administration and services and sales) comprising mainly of female employees.

\section{Part-time workers and Covid-19 vulnerability}

It was found that part-time workers are more likely to be vulnerable to COVID-19 (see figure 14 and 15). This could be driven by the fact that they are more likely to work in the two occupations that are considered to be most vulnerable - elementary administration and services and sales (55\% vs $45 \%$ for full time workers). Furthermore, they make up a large proportion of workers in wholesale and retail and accommodation and foods services, two of the most heavily impacted sectors. Relaxations to social distancing could also benefit these part-time workers to a greater extent too. Job vulnerability among part-time workers could reduce by $5-20 \%$ as a result of the measures, compared to $5-15 \%$ for full-time workers. In addition, it is likely that employers will favour flexible or phased return to work, to try to align labour availability with lower levels of demand in the short to medium term. 
Figure 12: Top 10 vulnerable occupations by gender

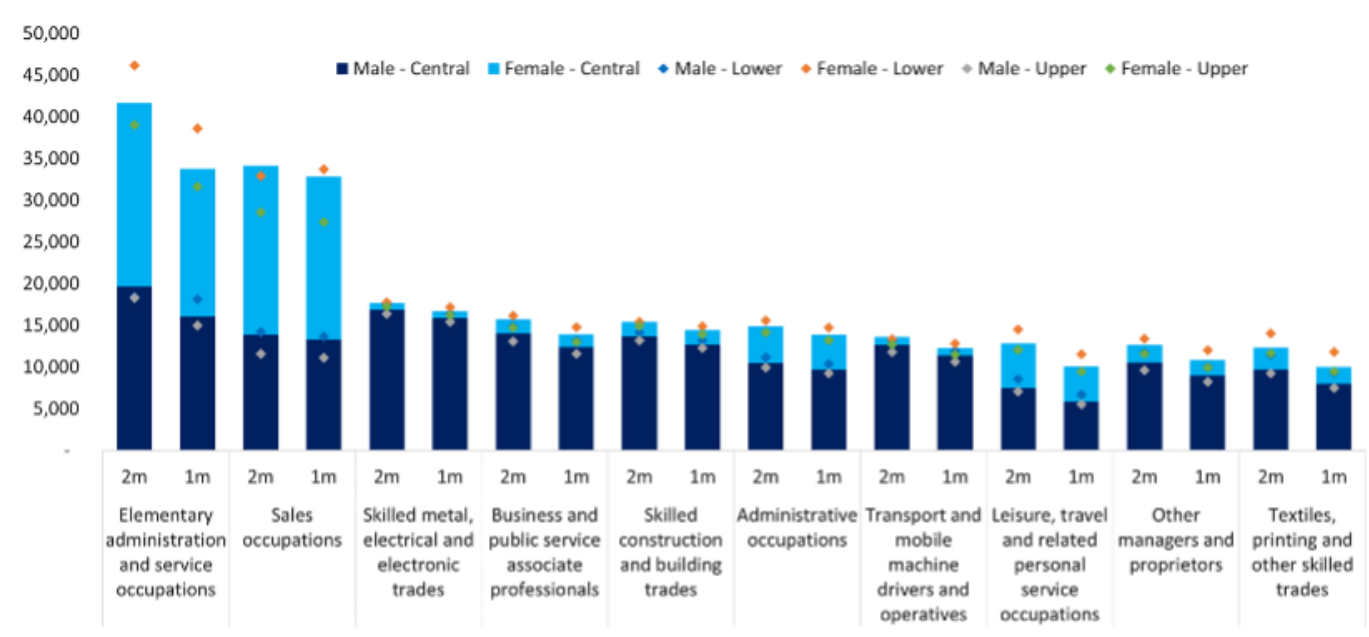

Figure 13: Top 10 vulnerable sectors by gender

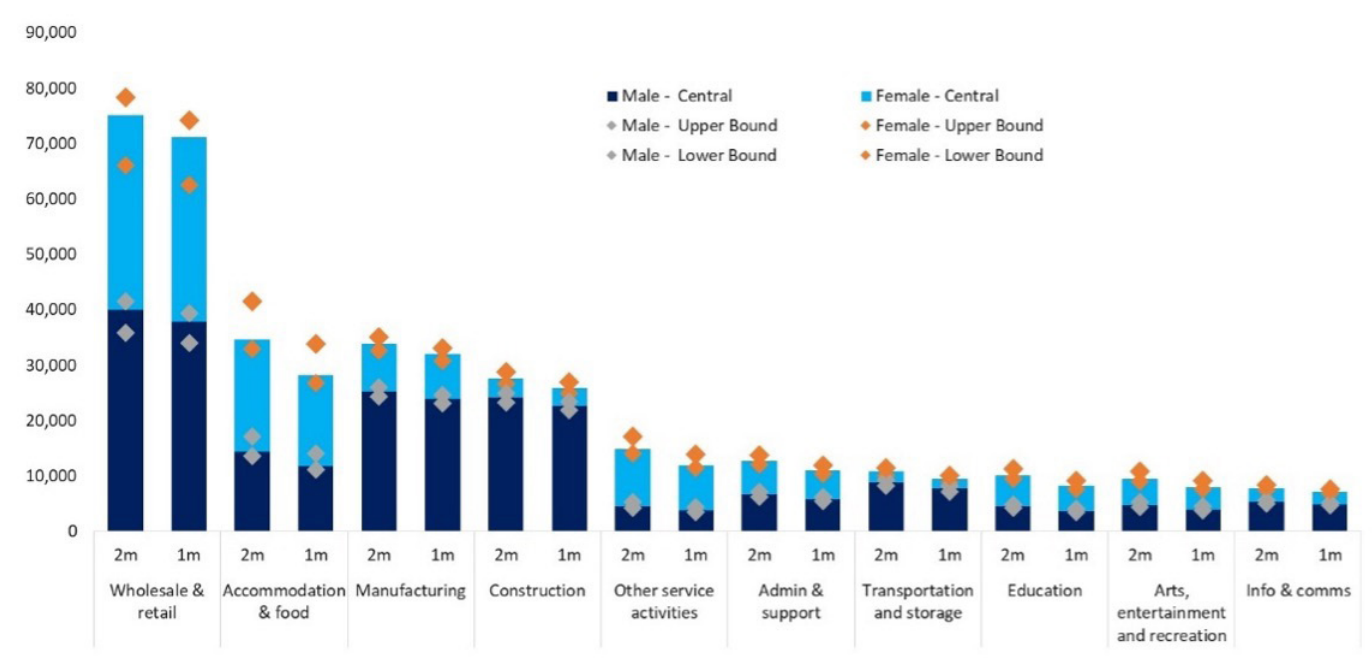

\section{Geographical perspective and job vulnerability}

It was found that the benefits of reducing social distancing requirements are relatively even across NI's council areas, ranging from a $10 \%$ to $13 \%$ reduction in the proportion of vulnerable jobs. As can be seen in figure 16 , MidUlster remains the most vulnerable council, with $29 \%$ of jobs considered vulnerable under the one-metre rule and $32 \%$ under the two-metre rule. Lisburn and Castlereagh remains the least vulnerable council area, with $24 \%$ of jobs considered vulnerable under the one-metre rule and $27 \%$ under the two-metre rule.

Importantly, and unlike trends exhibited in earnings and qualifications, the reduction in social distancing results in larger proportions of jobs remaining vulnerable in peripheral areas. Belfast, which was the third least vulnerable council area at the onset of the pandemic (with $29 \%$ of jobs considered vulnerable) is expected to see the greatest gains from reduction of social distancing requirements, with the number of vulnerable jobs falling by $13 \%$. In contrast, Mid Ulster, the most vulnerable council area at the start of the pandemic, is expected to see the second smallest reduction in vulnerable jobs, of $10 \%$. This is shown in figure 17. 
Figure 14: Top 10 vulnerable occupations by full-time, part-time

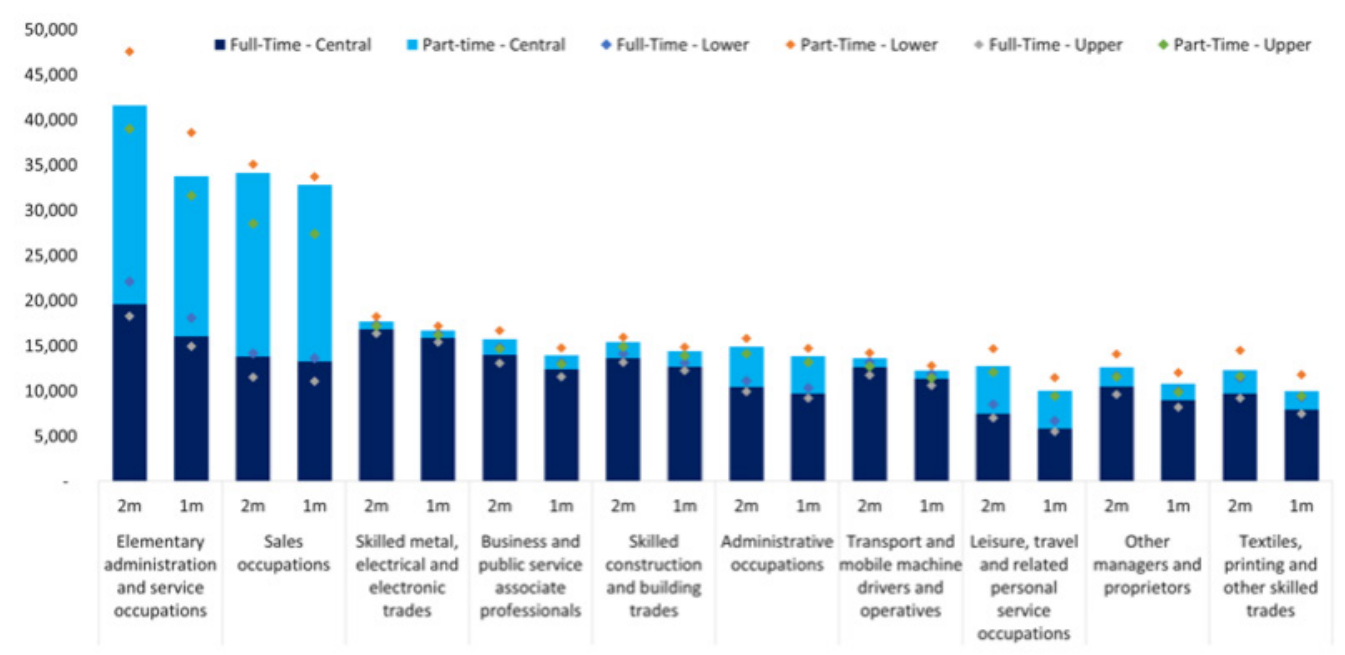

Figure 15: Top 10 vulnerable sectors by full-time, part-time

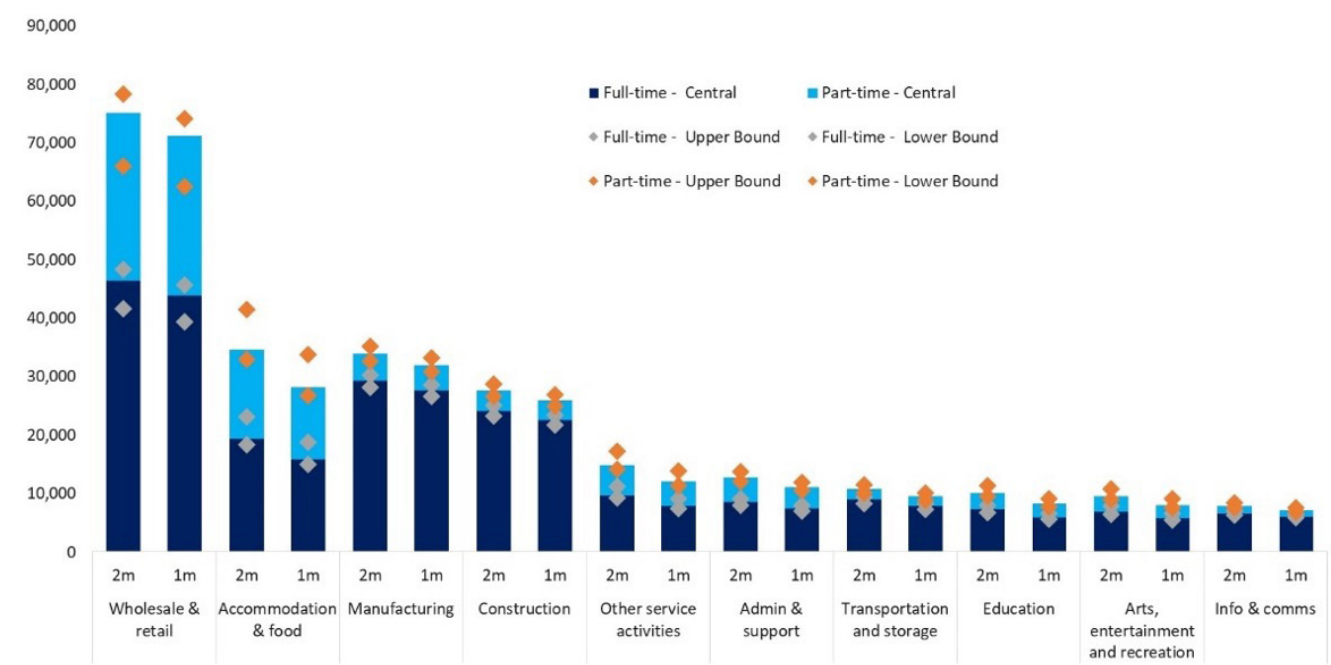

Figure 16: Vulnerable jobs by council area as share of employment at both 2-metre and 1-metre social distancing

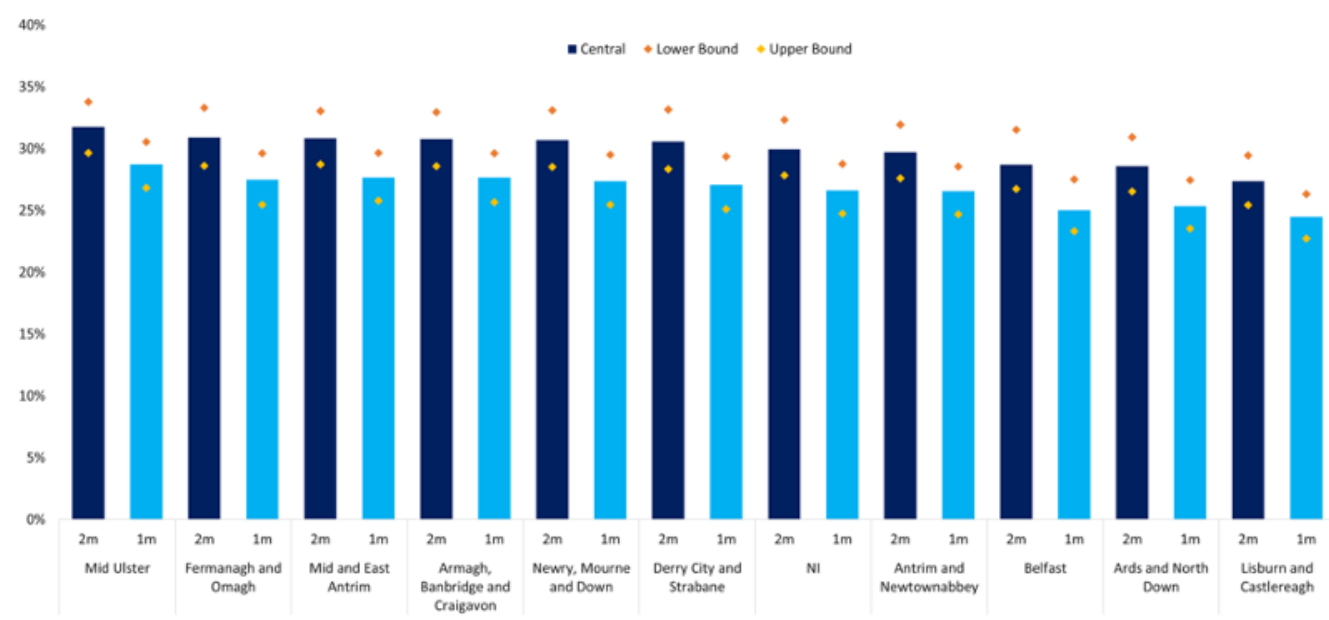


Figure 17: Reduction in vulnerable jobs as share of total by council area

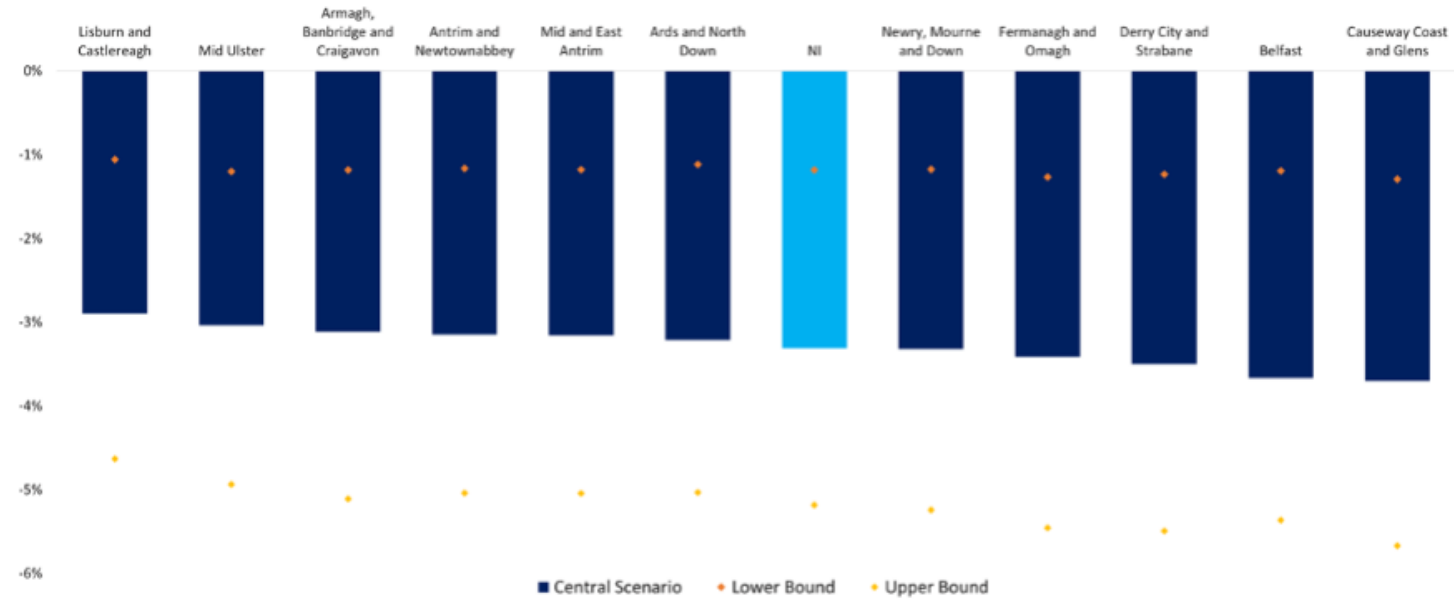

\section{DISCUSSION}

Overall, we identify that the social distancing and demand reduction due to the COVID-19 restrictions had a significant economic impact in NI. It potentially added 35,000 individuals to the unemployment register, 240,000 to the CJRS support register and 76,000 self-employed needed support through the SEISS. Our model also estimates GVA contractions ranging from $6-13 \%$ during July 2020. Similar to research on the 2008 economic recession (Sironi, 2018; Gesthuizen and Wolbers, 2010), our findings suggest that COVID-19 has the potential to leave long lasting impacts on the economy. Our modelling suggested that $240,000-280,000$ jobs were considered to be vulnerable as a result of the restrictions under a 2-metre social distancing requirement. This number was found to reduce to $215,000-250,000$ under the 1-metre social distancing requirement, removing around 30,000 jobs from vulnerability. This signals that a reduction in social distancing is a significant element in aiding the economic recovery policy for $\mathrm{NI}$.

It was found that the initial economic impact of COVID-19 varied widely across different groups. Indeed, concurring with prior research on prior economic recessions (Higgins, 2014; Sironi, 2018; Papadopoulos, 2016), COVID-19 impacted younger age groups and those without formal qualifications more significantly than older age groups and those with higher levels of formal qualifications (Cairo and Cajner, 2018; Gebel and Giesecke, 2011). However, we also provide new insights into the impact crises may have across gender and geography. Furthermore, we extend literature by considering the role technological advancement has had on companies' response to COVID-19 (Wendt et al. 2021; Riom and Valero, 2020). We show that sectors which can operate in a digital environment easily were less at risk. Service based occupations such as ICT and finance, which were not predominantly customer facing, were able to adjust to home-based working. In contrast, sectors such as hospitality and retail, which on average require relatively lower levels of formal qualification and have a more youthful and part-time worker profile, were much more likely to become vulnerable (Harms et al. 2021). There were also sectors which have benefited from COVID-19 through an increase in demand, such as those engaging in e-commerce or the manufacture of food products. It was found that by relaxing social distancing regulations to 1-metre, up to 10,000 job holders in the elementary administration and services and sales occupations would be removed from the vulnerable classification.

\section{Reductions in social distancing regulations should help the most vulnerable}

Our modelling showed that individuals who have lower levels of formal qualification, lower incomes, young people, males and part-time workers benefit most from the reduction in social distancing requirements. However, despite this, these individuals remain the most vulnerable groups in society and are more at risk now than prior to COVID-19. Consequently, policy interventions are needed to target the most vulnerable not only at times of crises but during stability.

It is noteworthy that council areas around Belfast, which were relatively more robust in economic terms prior to COVID-19, are those that benefit most from the reduction in social distancing, due to the concentration of retail and 
hospitality in those areas. More peripheral areas (that already lagged in economic terms) will benefit less from the reduction in social distancing. Therefore, it is apparent that the recovery could widen the economic gap between the strongest and weakest sub-regions of NI. This concurs with Zenka et al. (2019) who identifies that peripheral areas are more at risk during a crisis. Table 3 provides a summary demographic and geographic overview of those most impacted by COVID-19. Those based in customer facing roles with high sensitivity to demand constraints are most vulnerable (on an occupational and sectoral basis). These areas make up a significant share of the $\mathrm{NI}$ labour market and this will accordingly have implications for the wider $\mathrm{NI}$ economy. Individuals who are working in vulnerable areas tend to be young, earn less than the median wage and typically possess low levels of formal qualifications. Drawing from prior research on the impact crises can have on the young (Sironi, 2018; O'Higgins, 2014), it can be suggested that any job loss that ensues from this vulnerability is therefore more likely to result in long-term unemployment. Therefore, policy should implement pre-emptive interventions in order to prevent large proportions of these groups from losing their job in a short space of time.

Table 3: Distributional vulnerabilities of COVID-19, 2-metre and 1-metre

\begin{tabular}{cccccc}
\hline Category & $\begin{array}{c}\text { Most Vulnerable group } \\
\text { / area }\end{array}$ & 2-Metre & \% of group & 1-Metre & \% of group \\
\hline \hline Occupation & Elementary Admin' \& services ${ }^{6}$ & $40,000-50,000$ & $56-69 \%$ & $30,000-40,000$ & $46-56 \%$ \\
Sector & Wholesale \& retail & $65,000-80,000$ & $48-57 \%$ & $60,000-75,000$ & $46-54 \%$ \\
Qualification & Below level 2 NQF & $70,000-80,000$ & $39-45 \%$ & $60,000-70,000$ & $34-40 \%$ \\
Age & $16-24$-year-olds & $40,000-45,000$ & $36-43 \%$ & $30,000-40,000$ & $32-38 \%$ \\
Income & $<£ 15,000$ per annum & $65,000-80,000$ & $32-41 \%$ & $55,000-70,000$ & $29-36 \%$ \\
Gender & Males & $145,000-150,000$ & $32-34 \%$ & $130,000-145,000$ & $29-33 \%$ \\
Council Area & Mid Ulster & $19,000-22,000$ & $30-34 \%$ & $17,000-20,000$ & $27-31 \%$ \\
Part-Time / Full-Time & Part-Time & $65,000-80,000$ & $30-37 \%$ & $55,000-70,000$ & $26-32 \%$ \\
\hline
\end{tabular}

Note: individual rows do not sum to the total, as there are significant overlaps between categories.

\section{Demand remains the key issue}

Whilst job vulnerabilities and the associated risk to the economy is mitigated partially by the reduction in social distancing requirements, our research concurs with prior research on recession crises, where demand is the key driver of vulnerability during a crisis (Myant et al. 2016; Ashford et al. 2012). Therefore, stimulating demand is crucial to facilitate the recovery of the economy in the longer term. To illustrate this risk, if just $10 \%$ of those vulnerable posts do not have the demand to sustain them, the outcome would translate to a claimant unemployment rate of $10 \%$.

The UK Summer Budget 2020 resulted in the implementation of UK wide policies to boost consumer demand. This included the Kickstarter programme, CJRS returners bonus, VAT reductions for the most impacted sectors, a Stamp Duty holiday for house buyers and the "Eat Out to Help Out" voucher scheme. However, consumer habits change during a recession (Ashford et al. 2012), where it has been suggested that consumers dedicate more time to shopping, however, search for lower prices and identify substitutes (McKenzie et al. 2011). Indeed, the contagion of COVID-19 has led to an acceleration of online spending which impacts local companies. Based on our findings, we suggest that further mechanisms are needed to stimulate local demand in order to reduce job vulnerability. These could take the form of:

- An Nl-based voucher scheme to encourage consumption in the hardest hit sectors;

- Rates relief for domestic ratepayers to increase disposable household income and boost consumption;

- Expedited planning for economically significant investments, especially in rural areas;

- Investments that focuses on infrastructure, technology and competitiveness;

- Locally focussed procurement of goods and services;

- Further reductions of social distancing when the balancing of healthcare risks permit; and

6 Figures refer to proportion of employees in the sector 
- $\quad$ Focussing on emerging sectors that can generate employment and income in the future.

\section{Vulnerable groups will require further support}

It is clear from this research that in general, vulnerable groups will benefit most from the relaxation of social distancing requirements. Public policy should support the most vulnerable groups and those most in need in order minimise the risks of longer-term damage and scarring effects as a result of non-employment (Martin and Sunley, 2015; Benner, 2012). The winding down of the CJRS, and introduction of the Job Support Scheme (JSS) signalled a movement towards supporting businesses that are deemed 'viable'. From November 2020, additional supports for NI workers and businesses were added. This included:

- Coronavirus Job Support Scheme;

- $\quad$ Rates holiday for businesses;

- Rates relief in hospitality tourism, leisure and childcare sectors;

- $\quad$ COVID-19 Statutory sick pay rebate;

- $\quad$ HMRC Deferral of self-assessment payment

- Deferral of VAT payments;

- Organisations emergency programme for arts organisations;

- Small business grants.

However, despite this, there will be several issues left unresolved by these measures. This includes freelancers and the self-employed, those reskilling, and individuals forced to remain in hibernation due to health concerns lasting longer than expected. Therefore, targeted policy supports are needed for these individuals. Furthermore, we suggest that that economic and labour market shifts will impact the economy for some time. This will require the redistribution of skills and training; especially in digital technologies to cope with job displacement (Kraus et al. 2021b; Gesthuizen and Wolbers, 2010). It is suggested that individuals will be going back to work in an economy that has experienced rapid structural change as the recession accelerated existing trends associated with the fourth industrial revolution.

\section{CONCLUSIONS}

COVID-19 is the largest shock that the NI economy has experienced in its history. At present, policy and decision makers globally are actively trying to balance healthcare and economic risks and as both will continue to evolve, any further outbreaks of COVID-19 could shift the balance either way. In this paper, we set out to explore the influence Covid-19 has had on job vulnerability across different occupations and groups during the first wave of the COVID-19 crisis (spring and summer of 2020). Our findings have several contributions for theory. We provide new insights into how COVID-19 may impact sectors, age groups, individuals with varying qualification levels, gender and geographies differently. Therefore, we extend prior crisis management research by emphasising the need for regionally focussed policy making during a crisis. We also contribute to the public policy literature through demonstrating the complexity that COVID-19 poses for policy, strategy and implementation. Through our findings, we demonstrate the challenges of balancing public health with economic recovery. Furthermore, we contribute to new knowledge on how to map the economic impacts COVID-19 can have in real time through our point-in-time analysis. We identify how to adapt measures to different regional contexts, which can be repeated to aid policy decision making.

Our findings also have several implications for policy and practice. Our study illustrates the importance of both regional and interregional based policy responses due to potential variances in vulnerability across sectors, demography and geographies. Our findings also can be used as an evidence base for policy makers who are making future decisions over the use of social distancing measures and potential implications on job vulnerabilities. Our data indicates that demand will likely remain the primary impediment to job growth in the economy for the remainder of the crisis. This has implications for policy and identifies the need for policymakers to balance income retention that prevents scarring effects, with output growth that ultimately reduces the need for government support. Based on our findings, it is suggested that policy responses need to remain fluid. This could follow contingent strategies depending on if rates are low (such as evidenced by the Government's incentivisation scheme "Eat Out 
to Help Out") or high (implementing more generous income retention policies like CJRS). Specific policies that could be considered in the future in order to alleviate the future impacts of Covid-19 are:

- More generous job support schemes in vulnerable occupational and industry groups;

- Grants and subsidies for businesses expanding in occupations easily distanced;

- Vouchers for takeaway and delivery outlets;

- Extension of rates relief for impacted sectors;

- Support for companies transitioning to digitalisation;

- Public projects that utilise high-vulnerability occupations e.g. arts and creative industries;

- Case-by-case assessment of events / activities where economic value is balanced with strong health and safety measures; and

- Reskilling initiatives based on occupational characteristics and wider structural demand trends.

\section{Limitations and areas for future research}

Like all research, this study was bound by some limitations. Whilst we illustrate that our point-in-time model was useful to predict job vulnerability during a crisis, it cannot comment on exactly which jobs will be lost. This is due in large part to the intervention of CJRS and a lack of comparable crisis and policy interventions for reference. There is also a lack of data to be able to provide comparable job vulnerability levels prior to Covid-19. Furthermore, the pointin-time approach, which is adjusted for contextual regional characteristics of $\mathrm{NI}$, limits this model's exact replication in future studies. Future use of this point-in-time approach and methodology will need to consider fluctuations relating to sectoral demand, innovation, technological progress, and government support. These elements will need to be adapted across regions and allow for temporal attributes. Furthermore, whilst this study is discussing the economic implications of a health pandemic, it was out of the scope of this study to be able to model the trade-off between social distancing reductions and potential increases in virus transmission or public health implications. The characterisation of occupations utilised in this study could be expanded beyond analysis of health risks and draw comparisons between the skill sets of those more or less exposed to the risks of COVID-19. This would allow a preemptive assessment of likely patterns of labour re-allocation in response to COVID-19. Labour re-allocation between sectors is historically rare, with Davis and Haltiwanger (1992) finding that intra-industry reallocation accounted for only $13 \%$ of annual excess job reallocation in the 1970 s and 1980s in US manufacturing. However, we are operating within unique times and the growth of automation suggests that skills are increasingly transferrable in the modern economy, which should ease some allocative frictions. Future analysis may also compare vulnerability findings with actual redundancy data. This will allow for baseline models that can give an idea of vulnerability in the economy in normal times. Such a study would allow policymakers to respond more quickly to shocks in the future. It will also be important to assess vulnerability in a 'with-COVID world'. While removal of social distancing would theoretically reduce vulnerability in this model to zero, the impacts of economic scarring and changing consumer behaviours will ultimately leave a significant number of jobs in long-term vulnerability or redundancy. New analysis for longterm vulnerability could focus on sectoral demand patterns, skill loss, labour supply, educational attainment, and consumer confidence and behaviours, among others.

\section{References}

Arpaia, A. and Curci, N. (2010). EU labour market behaviour during the great Recession, Working paper from the Department of the Treasury, Ministry of the Economy and of Finance, Available online: https://ec.europa.eu/economy_finance/ publications/economic_paper/2010/pdf/ecp405_ en.pdf [accessed $10^{\text {th }}$ May 2021].

Ashford, N., Hall, R.P. and Ashford, R.H. (2012). The crisis in employment and consumer demand: Reconciliation with environmental sustainability, Environmental Innovation and Societal Transitions, 2, 1-22.
Bank of England, (2020). Monetary Policy Report, Available online: https://www.bankofengland. co.uk/-/media/boe/files/monetary-policyreport/2020/may/monetary-policy-report-may-2020 [accessed 13th May 2021].

Bardhan, A. and Tang, J. (2010). What Kind of Job is Safer? A Note on Occupational Vulnerability, The B.E. Journal of Economic Analysis \& Policy, 10 (1), 1-17.

Benito, A. (2005). Does job insecurity affect household consumption? Bank of England Working Paper, No. 220. 
Benner, M. (2012). Innovation policy in hard times: Lessons from the Nordic countries, European Planning Studies, 20 (9), 1455-1468.

Birnie, E., Johnson, R., Heery, L. and Ramsey, E. (2019). A critical review of competitiveness measurement in Northern Ireland, Regional Studies, 53 (10), 1494-1504.

Boeri, T. and Bruecker, H. (2011). Short-time work benefits revisited: some lessons from the Great Recession, Economic Policy, 26(68), 697-765.

Breier, M., Kallmuenzer, A., Clauss, T., Gast, J., Kraus, S. and Tiberius, V. (2021). The role of business model innovation in the hospitality industry during the Covid-19 crisis, International Journal of Hospitality Management, 92, 102723.

Cairo, I. and Cajner, T. (2018). Human Capital and Unemployment Dynamics: Why More Educated Workers Enjoy Greater Employment Stability, The Economic Journal, 128 (609), 652-682.

Clauss, T., Breier, M., Kraus, S., Durst, S. and Mahto, R.V. (2021). Temporary business model innovation - SMEs' innovation response to the Covid-19 crisis, $R \& D$ Management, Early Online View.

Davis, S.J. and Haltiwanger, J. (1992). Gross Job Creation, Gross Job Destruction, and Employment Reallocation. Quarterly Journal of Economics, 107, 3, 819-863.

Department for Business, Energy and Industrial Strategy (BEIS) (2019). UK National Innovation Survey, Available online: https://assets.publishing.service. gov.uk/government/uploads/system/uploads/ attachment_data/file/903582/UK_Innovation_ Survey_2019_Main_Report.pdf [Accessed 01/11/20].

Dietrich, H. (2013). Youth unemployment in the period 2001-2010 and the European crisis - looking at the empirical evidence, European Review of Labour and Research, 19, 3, 305-324.

Eugenio Martin, J.L. and Campos-Soria, J.A. (2014). Economic crisis and tourism expenditure cutback decision, Annals of Tourism Research, 44, 53-73.

European Parliament Briefing (2018). NI After Brexit. Available online: https://www.europarl.europa. eu/RegData/etudes/BRIE/2020/649416/EPRS BRI(2020)649416_EN.pdf accessed 01/11/20

Faulkner, N. and Kaufman, S. (2017). Avoiding Theoretical Stagnations: A systematic review and framework for measuring public value, Australian Journal of Public Administration, 77, (1), 69-86.

Ferrante, G., Baldissera, S., Moghadam, P.F., Carrozzi, G., Trinito, M.O. and Salmaso, S. (2011). Surveillance of perceptions, knowledge, attitudes and behaviours of the Italian adult population (18-
69 years) during the 2009-2010 A/H1N1 influenza pandemic, European Journal of Epidemology, 26, (3), 211-219.

Foss, N. J. (2020). The impact of The Covid $\square 19$ pandemic on firms' organizational designs, Journal of Management Studies, 58, 68-272.

Ganong, P. and Noel, P. (2015). Consumer spending during unemployment: Positive and normative implications, American Economic Review, 109, (7), 2383-2424.

Gebel, M. and Giesecke, J. (2011). Labour market flexibility and inequality: The changes skill-based temporary employment and unemployment risks in Europe, Social Forces, 90, (1), 17-39.

Gesthuizen, M. and Wolbers, M.H. J. (2010). Employment transitions in the Netherlands, 19802004: Are low educated men subject to structural or cyclical crowding out? Research in Social Stratification and Mobility, 28, 43751.

Goddard, N. L., Delpech, V.C., Watson, J.M., Regan, M. and Nicoll, A. (2006). Lessons learned from SARS: The experience of the Health Protection Agency, England. Public Health, 120 (1), 27-32.

Harms, R., Alfert, C., Cheng, C.F. and Kraus, S. (2021). Effectuation and causation configurations for business model innovation: Addressing Covid-19 in the gastronomy industry, International Journal of Hospitality Management, 95, 10289.

HM Treasury, (2011). Rebalancing the NI Economy. Available online: https://assets.publishing.service. gov.uk/government/uploads/system/uploads/ attachment_data/file/81554/rebalancing_the northern_ireland_economy_consultation.pdf [Accessed 01/11/2020].

International Monetary Fund (IMF) (2020). World Economic Outlook, Unemployment Rate, Available online: https://www.imf.org/external/datamapper/ LUR@WEO/NOR [Accessed 01/11/20].

Jiang, J., Chen, E., Yan, S., Lerman, K. and Ferrara, E. (2020). Political polarisation drives online conversations about COVID-19 in the United States, Human Behaviour and Emerging Technologies, 2 (3), 200-211.

Kalleberg, A. L. (1996). "Changing contexts of careers: Trends in labor market structures and someimplications for labor market outcomes", in Kerckhoff, A.C., Generating Social Stratification: Toward a New Research Agenda, pp. 343-358, Westview Press, Boulder, CO.

Keynes, J.M., Krugman, P.R. and Skidelsky, R.J.A. (2018). The general theory of employment, interest, and money, Cham, Switzerland: Palgrave Macmillan. 
Klein, J.P., Logan, B., Harhoff, M. and Andersen P.K. (2007). Analyzing survival curves at a fixed pointin-time, Statistics in Medicine, 26 (24), 4505-4519.

Kraus, S., Clauss, T., Breier, M., Gast, J., Zardini, A. and Tiberius, V. (2020). The economics of Covid-19: initial empirical evidence on how family firms in five European countries cope with the corona crisis, International Journal of Entrepreneurial Behaviour and Research, 26(5), 1067-1092.

Kraus, S., McDowell, A., Ribeiro-Soriano, D.E. and Rodriquez-Garcia, M. (2021a). The role of innovation and knowledge for entrepreneurship and regional development, Entrepreneurship and Regional Development, 33(3-4), 175-184.

Kraus, S., Jones, P., Kailer, N., Weinmann, A., ChaparroBanegas, N. and Roig-Tierno, N. (2021b). Digital transformation: An overview of the current state of the art of research, Sage Open, 11 (3), 21582440211047576.

Lydon, R., Matham T.Y. and Millard, S. (2019). Short-time work in the Great Recession: firm level evidence from 20 EU countries, IZA Journal of Labour Policy, 8 (2), 1906.

Martin, R. and Sunley, P. (2015). On the notion of economic resilience: conceptualisation and explanation, Journal of Economic Geography, 15 (1), 1-42.

Magill, M. and McPeake, M. (2016). An Anatomy of Economic Inactivity in Northern Ireland; Ulster University Economic Policy Centre, November.

Magill, M. and McPeake, M., (2020). How have restrictions on work impacted different types of workers in Northern Ireland. [online] Ulster.ac.uk. Available at: https://www.ulster.ac.uk/_data/ assets/pdf_file/0004/578263/COVID-19-Workercharacteristics_08.06.2020.pdf [Accessed 6 May 2021].

McGann, M. (2020). The political economy of welfare in a time of coronavirus: Post-productivism as a state of exception, Irish Journal of Sociology, 28 (2), 225-230.

McKenzie, D., Schargrodsky, E., and Cruces, G. (2011). Buying less but shopping more: The use of nonmarket labour during a crisis, Economia, 11 (2), $1-43$

Myant, M., Theodoropoulou, S. and Piasna, A. (2016). Unemployment, Internal Devaluation and Labour Market Deregulation in Europe. Brussels, Belgium: European Trade Union Institute.

McKinsey \& Company (2020). Lives and livelihoods: Assessing the near-term impact of COVID-19 on US workers, Available online: https://www.mckinsey.com/industries/public-and-social-sector/our- insights/lives-and-livelihoods-assessing-the-nearterm-impact-of-covid-19-on-us-workers [Accessed 01/11/2020]

Neal, D. (1998). The Link between Ability and Specialization: An Explanation for Observed Correlations between Wages and Mobility Rates, The Journal of Human Resources, 33 (1), 173-200.

NI Chamber of Commerce (2020). NI Chamber of Commerce \& BDO: first insight into major economic impact of COVID-19. [online] Available at: https:// www.northernirelandchamber.com/2020/04/08/nichamber-bdo-survey-first-insight-major-economicimpact-covid-19/ [Accessed 6 May 2021].

NISRA (2011). 2011 Census. Available online: https:// www.nisra.gov.uk/statistics/census/2011-census [Accessed 13th May 2021].

Onet (2021). Department of Labor O*NET, Occupational characteristics. Available online: https://www.onetonline.org/ [Accessed 10 $10^{\text {th }}$ May 2021].

ONS, (2020). Employment and employment types. Available online: https://www.ons.gov.uk/employmentandlabourmarket/peopleinwork/employmentandemployeetypes [Accessed $10^{\text {th }}$ May 2021].

ONS (2021a). Which occupations have the highest potential exposure to the coronavirus (COVID-19)? - Office for National Statistics. [online] Available at: https://www.ons.gov.uk/ employmentandlabourmarket/peopleinwork/ employmentandemployeetypes/articles/whichoccupationshavethehighestpotentialexposuretothecoronaviruscovid19/2020-05-11 [Accessed 6 May 2021].

ONS (2021b). Coronavirus and the economic impacts on the UK - Office for National Statistics. [online] Available at: https://www.ons.gov.uk/businessindustryandtrade/business/businessservices/bulletins/coronavirusandtheeconomicimpactsontheuk/1 6july2020 [Accessed 6 May 2021].

ONS (2019a). Labour Force Survey. Available online: https://www.ons.gov.uk/releases/uklabourmarketst atisticsjune2019[Accessed 13th May 2021].

ONS (2019b). Employee earnings in the UK: 2019, Available online: https://www.ons.gov.uk/employmentandlabourmarket/peopleinwork/earningsandworkinghours/bulletins/annualsurveyofhoursandea rnings/2019[Accessed 13th May 2021].

ONS, (2017). Young people not in education, employment or training (NEET) Available online: https:// www.ons.gov.uk/employmentandlabourmarket/ peoplenotinwork/unemployment/bulletins/youngpeoplenotineducationemploymentortrainingneet/ feb2017[Accessed 13th May 2021]. 
Office for Budget Responsibility (OBR) (2020). Coronavirus Analysis. Available online: https:// obr.uk/coronavirus-analysis/ [Accessed 14 ${ }^{\text {th }}$ May 2021].

O'Higgins, N. (2014). "Rising to the youth employment challenge: New Evidence on Policy Issues". International Labour Organisation.

Panovska-Griffiths (2020). Can mathematical modelling solve the current COVID-19 Crisis? BMC Public Health, 20 (551), 1-15.

Papatheodorou, A., Rosselló, J. and Xiao, $\mathrm{H}$. (2010). Global Economic Crisis and Tourism: Consequences and Perspectives, Journal of Travel Research, 49(1), 39-45.

Papadopoulos, O. (2016). Economic crisis and young unemployment: Comparing Greece and Ireland, European Journal of Industrial Relations, 22 (4), 409-426.

Peck, J. and Theodore, N. (2007). Flexible recession: the temporary staffing industry and mediated work in the United States, Cambridge Journal of Economics, 31 (2), 171-192.

Pettigrew, S., Anderson, L., Boland, W, de La Ville, V-I., Fifta, I.M.E., Fosse-Gomez, M-H, Kindt, M., Lukkanen, L., Martin, I., Ozanne, L.K., Pirouz, D.M., Prothero, A. and Stovall, T. (2014). The experience of risk in families: Conceptualisations and implications for transformative consumer research, Journal of Marketing, 30 (17-18), 17721799.

PWC, (2016). Northern Oreland Economic Outlook: Avoiding Recession. Available online: https://www. pwc.co.uk/who-we-are/regions/northernireland/ nieo-130916.pdf PWC 2016 [Accessed 01/11/20].

Regester, M. and Larkin, J. (2002). Risk Issues and crisis Management, Kogan Page Publishers.

Riom, C. and Valero, A. (2020). The business response to Covid-19: the CEP-CBI survey on technology adoption, London School of Economics, Centre for Economic Performance, Available online: https://cep.Ise.ac.uk/_new/publications/abstract. asp?index $=7291$ [Accessed $10^{\text {th }}$ May 2021].

Rowthorn, B. (1981). Northern Ireland: An economy in crisis, Cambridge Journal of Economics, 5 (1), 1-31.

Schatz, B.R. and Berlin R.B. Jr (2011). Public Health Failure when Complex, Healthcare infrastructure, Health Informatics, Springer, London.

Schiliro, D., (2013). Bounded rationality: Psychology, economics and the financial crises, Theoretical and Practical research in Economic Fields, 7, 97-108.
Shankar, K. (2020). The impact of COVID-19 on IT services industry - Expected transformations, British Journal of Management, 31 (3), 450-452.

Sharma, A., Bikash Borah, S. and Moses, A.C. (2021). Responses to COVID-19: The role of governance, healthcare infrastructure and learning from past pandemics. Journal of Business Research, 122, 597-607.

Sharma, S., Singh, G., Sharma, R., Jones, P., Kraus, S. and Dwiedi, Y.K. (2020). Digital health innovation: Exploring the adoption of Covid-19 digital contact tracing apps. IEEE Transactions in Engineering Management, Early Online Access.

Sheth, J. (2020). Impact of COVID-19 on consumer behaviour: Will the old habits return or die? Journal of Business Research, Early online.

Shoss, M. K. (2017). Job insecurity: An integrative review and agenda for future research, Journal of Management, 43 (6), 1911-1939.

Sironi, M. (2018). Economic conditions of young adults before and after the great recession, Journal of Family and Economic Issues, 39, 103-116.

Surel, Y. (2000). The role of cognitive and normative frames in policy-making, Journal of European Public Policy, 7 (4), 495-512.

Teague, P. (2016). Northern Ireland: The Political Economy of Peace, Working Paper, Available online: https://www.qub.ac.uk/Research/GRI/mitchellinstitute/FileStore/Filetoupload,727473,en.pdf [Accessed 01/11/20].

UK Government (2020). Coronavirus (Covid-19) Guidance and Support. Available online: https:// www.gov.uk/coronavirus [Accessed 01/11/20].

Verick, S. (2009). "Who Is Hit Hardest during a Financial Crisis? The Vulnerability of Young Men and Women to Unemployment in an Economic Downturn", Discussion Paper No. 4359, International Labour Organization (ILO) and IZA.

Wachter, T. (2020). Lost generations: Long term effects of the COVID-19 crisis on job losers and labour market entrants and options for policy, Fiscal Studies, 41 (3), 549-590.

Wendt, C., Adam, M., Benlian, A. and Kraus, S. (2021). Let's connect to keep the distance: How SMEs leverage information and communication technologies to address the COVID-19 crisis. Information Systems Frontiers, 1, 1-19.

Wenzel, M., Stanske, S. and Lieberman, M.B. (2020). Strategic responses to crisis, Strategic Management Journal, 41, 7-18.

Williams, T.A., Gruber, D.A., Sutcliffe, K. and Zho, E.Y. (2017). Organisational response to adversity: Fusing Crisis Management and Resilience 
Research Streams, The Academy of Management Annals, 11 (2), 733-769.

Yang, K. (2020). Unprecedented Challenges, Familiar Paradoxes: COVID-19 and Governance in a new normal state of risks. Public Administration Review, 80 (4), 657-664.
Zenka, J., Slach, O. and Pavlik, A. (2019). Economic resilience of metropolitan, old industrial, and rural regions in two subsequent recessionary shocks, European Planning Studies, 27 (11), 2288-2311. 


\section{Annex 1: Baseline Social Distancing impacts, by occupation. 1m Social Distancing}

\begin{tabular}{|c|c|}
\hline Occupation & Risk level \\
\hline Chief executives and senior officials & Low \\
\hline Elected officers and representatives & Low \\
\hline Production managers and directors in manufacturing & Low \\
\hline Production managers and directors in construction & Low \\
\hline Production managers and directors in mining and energy & Low \\
\hline Financial managers and directors & Low \\
\hline Marketing and sales directors & Low \\
\hline Purchasing managers and directors & Low \\
\hline Advertising and public relations directors & Low \\
\hline Human resource managers and directors & Low \\
\hline Information technology and telecommunications directors & Low \\
\hline Functional managers and directors n.e.c. & Low \\
\hline Financial institution managers and directors & Low \\
\hline Managers and directors in transport and distribution & Low \\
\hline Managers and directors in storage and warehousing & Low \\
\hline Officers in armed forces & High \\
\hline Senior police officers & High \\
\hline Senior officers in fire, ambulance, prison and related services & High \\
\hline Health services and public health managers and directors & Medium \\
\hline Social services managers and directors & High \\
\hline Managers and directors in retail and wholesale & Low \\
\hline Managers and proprietors in agriculture and horticulture & Low \\
\hline Managers and proprietors in forestry, fishing and related services & Low \\
\hline Hotel and accommodation managers and proprietors & Medium \\
\hline Restaurant and catering establishment managers and proprietors & High \\
\hline
\end{tabular}


Occupation

\begin{tabular}{|c|c|}
\hline Publicans and managers of licensed premises & High \\
\hline Leisure and sports managers & High \\
\hline Travel agency managers and proprietors & Medium \\
\hline Health care practice managers & Medium \\
\hline Residential, day and domiciliary care managers and proprietors & High \\
\hline Property, housing and estate managers & Medium \\
\hline Garage managers and proprietors & Low \\
\hline Hairdressing and beauty salon managers and proprietors & High \\
\hline Shopkeepers and proprietors: wholesale and retail & High \\
\hline Waste disposal and environmental services managers & Low \\
\hline Managers and proprietors in other services n.e.c. & High \\
\hline Chemical scientists & Low \\
\hline Biological scientists and biochemists & Low \\
\hline Physical scientists & Low \\
\hline Social and humanities scientists & Low \\
\hline Natural and social science professionals n.e.c. & Low \\
\hline Civil engineers & Low \\
\hline Mechanical engineers & Low \\
\hline Electrical engineers & Low \\
\hline Electronics engineers & Low \\
\hline Design and development engineers & Low \\
\hline Production and process engineers & Low \\
\hline Engineering professionals n.e.c. & Low \\
\hline IT specialist managers & Low \\
\hline IT project and programme managers & Low \\
\hline IT business analysts, architects and systems designers & Low \\
\hline Programmers and software development professionals & Low \\
\hline
\end{tabular}


Occupation

Risk level

\begin{tabular}{|c|c|}
\hline Web design and development professionals & Low \\
\hline Information technology and telecommunications professionals n.e.c. & Low \\
\hline Conservation professionals & High \\
\hline Environment professionals & Low \\
\hline Research and development managers & Medium \\
\hline Medical practitioners & High \\
\hline Psychologists & High \\
\hline Pharmacists & High \\
\hline Ophthalmic opticians & High \\
\hline Dental practitioners & High \\
\hline Veterinarians & High \\
\hline Medical radiographers & High \\
\hline Podiatrists & High \\
\hline Health professionals n.e.c. & High \\
\hline Physiotherapists & High \\
\hline Occupational therapists & High \\
\hline Speech and language therapists & High \\
\hline Therapy professionals n.e.c. & High \\
\hline Nurses & High \\
\hline Midwives & High \\
\hline Higher education teaching professionals & Low \\
\hline Further education teaching professionals & High \\
\hline Secondary education teaching professionals & Medium \\
\hline Primary and nursery education teaching professionals & High \\
\hline Special needs education teaching professionals & High \\
\hline Senior professionals of educational establishments & High \\
\hline Education advisers and school inspectors & High \\
\hline
\end{tabular}


Occupation

\begin{tabular}{|c|c|}
\hline Teaching and other educational professionals n.e.c. & High \\
\hline Barristers and judges & High \\
\hline Solicitors & Medium \\
\hline Legal professionals n.e.c. & Low \\
\hline Chartered and certified accountants & Low \\
\hline Management consultants and business analysts & Low \\
\hline Business and financial project management professionals & Low \\
\hline Actuaries, economists and statisticians & Low \\
\hline Business and related research professionals & Low \\
\hline Business, research and administrative professionals n.e.c. & Low \\
\hline Architects & Low \\
\hline Town planning officers & High \\
\hline Quantity surveyors & Medium \\
\hline Chartered surveyors & Medium \\
\hline Chartered architectural technologists & Low \\
\hline Construction project managers and related professionals & Low \\
\hline Social workers & High \\
\hline Probation officers & High \\
\hline Clergy & High \\
\hline Welfare professionals n.e.c. & High \\
\hline Librarians & High \\
\hline Archivists and curators & Medium \\
\hline Quality control and planning engineers & Low \\
\hline Quality assurance and regulatory professionals & Low \\
\hline Environmental health professionals & Low \\
\hline Journalists, newspaper and periodical editors & Medium \\
\hline Public relations professionals & Medium \\
\hline
\end{tabular}


Occupation

Risk level

\begin{tabular}{|c|c|}
\hline Advertising accounts managers and creative directors & High \\
\hline Laboratory technicians & High \\
\hline Electrical and electronics technicians & Low \\
\hline Engineering technicians & Medium \\
\hline Building and civil engineering technicians & Medium \\
\hline Quality assurance technicians & Low \\
\hline Planning, process and production technicians & Low \\
\hline Science, engineering and production technicians n.e.c. & Low \\
\hline Architectural and town planning technicians & High \\
\hline Draughtspersons & Low \\
\hline IT operations technicians & Low \\
\hline IT user support technicians & Low \\
\hline Paramedics & High \\
\hline Dispensing opticians & High \\
\hline Pharmaceutical technicians & High \\
\hline Medical and dental technicians & High \\
\hline Health associate professionals n.e.c. & High \\
\hline Youth and community workers & High \\
\hline Child and early years officers & High \\
\hline Housing officers & High \\
\hline Counsellors & High \\
\hline Welfare and housing associate professionals n.e.c. & High \\
\hline NCOs and other ranks & High \\
\hline Police officers (sergeant and below) & High \\
\hline Fire service officers (watch manager and below) & High \\
\hline Prison service officers (below principal officer) & High \\
\hline Police community support officers & High \\
\hline
\end{tabular}


Occupation

\begin{tabular}{|c|c|}
\hline Protective service associate professionals n.e.c. & High \\
\hline Artists & Low \\
\hline Authors, writers and translators & Low \\
\hline Actors, entertainers and presenters & High \\
\hline Dancers and choreographers & High \\
\hline Musicians & High \\
\hline Arts officers, producers and directors & Medium \\
\hline Photographers, audio-visual and broadcasting equipment operators & Low \\
\hline Graphic designers & Low \\
\hline Product, clothing and related designers & Low \\
\hline Sports players & Medium \\
\hline Sports coaches, instructors and officials & Medium \\
\hline Fitness instructors & High \\
\hline Air traffic controllers & High \\
\hline Aircraft pilots and flight engineers & High \\
\hline Ship and hovercraft officers & High \\
\hline Legal associate professionals & Low \\
\hline Estimators, valuers and assessors & Low \\
\hline Brokers & Low \\
\hline Insurance underwriters & Low \\
\hline Finance and investment analysts and advisers & Low \\
\hline Taxation experts & High \\
\hline Importers and exporters & Low \\
\hline Financial and accounting technicians & Low \\
\hline Financial accounts managers & Low \\
\hline Business and related associate professionals n.e.c. & Low \\
\hline Buyers and procurement officers & Low \\
\hline
\end{tabular}


Occupation

\begin{tabular}{|c|c|}
\hline Business sales executives & Medium \\
\hline Marketing associate professionals & Low \\
\hline Estate agents and auctioneers & High \\
\hline Sales accounts and business development managers & Low \\
\hline Conference and exhibition managers and organisers & High \\
\hline Conservation and environmental associate professionals & High \\
\hline Public services associate professionals & Low \\
\hline Human resources and industrial relations officers & Low \\
\hline Vocational and industrial trainers and instructors & Medium \\
\hline Careers advisers and vocational guidance specialists & High \\
\hline Inspectors of standards and regulations & Low \\
\hline Health and safety officers & Medium \\
\hline National government administrative occupations & Low \\
\hline Local government administrative occupations & Low \\
\hline Officers of non-governmental organisations & Low \\
\hline Credit controllers & Low \\
\hline Book-keepers, payroll managers and wages clerks & Low \\
\hline Bank and post office clerks & High \\
\hline Finance officers & High \\
\hline Financial administrative occupations n.e.c. & Medium \\
\hline Records clerks and assistants & Low \\
\hline Pensions and insurance clerks and assistants & Low \\
\hline Stock control clerks and assistants & High \\
\hline Transport and distribution clerks and assistants & High \\
\hline Library clerks and assistants & High \\
\hline Human resources administrative occupations & Low \\
\hline Sales administrators & High \\
\hline
\end{tabular}


Occupation

Risk level

\begin{tabular}{|c|c|}
\hline Other administrative occupations n.e.c. & Low \\
\hline Office managers & High \\
\hline Office supervisors & Low \\
\hline Medical secretaries & High \\
\hline Legal secretaries & Low \\
\hline School secretaries & High \\
\hline Company secretaries & Medium \\
\hline Personal assistants and other secretaries & Medium \\
\hline Receptionists & High \\
\hline Typists and related keyboard occupations & Medium \\
\hline Farmers & Low \\
\hline Horticultural trades & Low \\
\hline Gardeners and landscape gardeners & Medium \\
\hline Groundsmen and greenkeepers & Low \\
\hline Agricultural and fishing trades n.e.c. & Low \\
\hline Smiths and forge workers & High \\
\hline Moulders, core makers and die casters & Low \\
\hline Sheet metal workers & Low \\
\hline Metal plate workers, and riveters & Low \\
\hline Welding trades & Low \\
\hline Pipe fitters & Low \\
\hline Metal machining setters and setter-operators & Low \\
\hline Tool makers, tool fitters and markers-out & Low \\
\hline Metal working production and maintenance fitters & Low \\
\hline Precision instrument makers and repairers & Low \\
\hline Air-conditioning and refrigeration engineers & High \\
\hline Vehicle technicians, mechanics and electricians & High \\
\hline
\end{tabular}


Occupation

\begin{tabular}{|c|c|}
\hline Vehicle body builders and repairers & Low \\
\hline Vehicle paint technicians & Low \\
\hline Aircraft maintenance and related trades & Low \\
\hline Boat and ship builders and repairers & Low \\
\hline Rail and rolling stock builders and repairers & Medium \\
\hline Electricians and electrical fitters & Medium \\
\hline Telecommunications engineers & High \\
\hline TV, video and audio engineers & Medium \\
\hline IT engineers & Low \\
\hline Electrical and electronic trades n.e.c. & Medium \\
\hline Skilled metal, electrical and electronic trades supervisors & Low \\
\hline Steel erectors & Low \\
\hline Bricklayers and masons & Low \\
\hline Roofers, roof tilers and slaters & Low \\
\hline Plumbers and heating and ventilating engineers & High \\
\hline Carpenters and joiners & Low \\
\hline Glaziers, window fabricators and fitters & Medium \\
\hline Construction and building trades n.e.c. & Medium \\
\hline Plasterers & Medium \\
\hline Floorers and wall tilers & Low \\
\hline Painters and decorators & Low \\
\hline Construction and building trades supervisors & High \\
\hline Weavers and knitters & Low \\
\hline Upholsterers & Low \\
\hline Footwear and leather working trades & Low \\
\hline Tailors and dressmakers & Medium \\
\hline Textiles, garments and related trades n.e.c. & Low \\
\hline
\end{tabular}


Occupation

\begin{tabular}{|c|c|}
\hline Pre-press technicians & Low \\
\hline Printers & Low \\
\hline Print finishing and binding workers & Low \\
\hline Butchers & High \\
\hline Bakers and flour confectioners & Low \\
\hline Fishmongers and poultry dressers & Medium \\
\hline Chefs & High \\
\hline Cooks & Medium \\
\hline Catering and bar managers & High \\
\hline Glass and ceramics makers, decorators and finishers & Low \\
\hline Furniture makers and other craft woodworkers & Low \\
\hline Florists & High \\
\hline Other skilled trades n.e.c. & Low \\
\hline Nursery nurses and assistants & Low \\
\hline Childminders and related occupations & High \\
\hline Playworkers & High \\
\hline Teaching assistants & High \\
\hline Educational support assistants & High \\
\hline Veterinary nurses & High \\
\hline Pest control officers & High \\
\hline Animal care services occupations n.e.c. & High \\
\hline Nursing auxiliaries and assistants & High \\
\hline Ambulance staff (excluding paramedics) & High \\
\hline Dental nurses & High \\
\hline Houseparents and residential wardens & High \\
\hline Care workers and home carers & High \\
\hline Senior care workers & High \\
\hline
\end{tabular}


Occupation

\begin{tabular}{|c|c|}
\hline Care escorts & High \\
\hline Undertakers, mortuary and crematorium assistants & High \\
\hline Sports and leisure assistants & High \\
\hline Travel agents & Medium \\
\hline Air travel assistants & High \\
\hline Rail travel assistants & Low \\
\hline Leisure and travel service occupations n.e.c. & High \\
\hline Hairdressers and barbers & High \\
\hline Beauticians and related occupations & High \\
\hline Housekeepers and related occupations & High \\
\hline Caretakers & High \\
\hline Cleaning and housekeeping managers and supervisors & High \\
\hline Sales and retail assistants & High \\
\hline Retail cashiers and check-out operators & High \\
\hline Telephone salespersons & Low \\
\hline Pharmacy and other dispensing assistants & High \\
\hline Vehicle and parts salespersons and advisers & High \\
\hline Collector salespersons and credit agents & Low \\
\hline Debt, rent and other cash collectors & High \\
\hline Roundspersons and van salespersons & Low \\
\hline Market and street traders and assistants & High \\
\hline Merchandisers and window dressers & Medium \\
\hline Sales related occupations n.e.c. & High \\
\hline Sales supervisors & Medium \\
\hline Call and contact centre occupations & Low \\
\hline Telephonists & High \\
\hline Communication operators & Low \\
\hline
\end{tabular}


Occupation

\begin{tabular}{|c|c|}
\hline Market research interviewers & Low \\
\hline Customer service occupations n.e.c. & Medium \\
\hline Customer service managers and supervisors & Medium \\
\hline Food, drink and tobacco process operatives & Low \\
\hline Glass and ceramics process operatives & Low \\
\hline Textile process operatives & Low \\
\hline Chemical and related process operatives & Low \\
\hline Rubber process operatives & Low \\
\hline Plastics process operatives & Low \\
\hline Metal making and treating process operatives & Low \\
\hline Electroplaters & Low \\
\hline Process operatives n.e.c. & Low \\
\hline Paper and wood machine operatives & Low \\
\hline Coal mine operatives & Low \\
\hline Quarry workers and related operatives & Low \\
\hline Energy plant operatives & Low \\
\hline Metal working machine operatives & Low \\
\hline Water and sewerage plant operatives & High \\
\hline Printing machine assistants & Low \\
\hline Plant and machine operatives n.e.c. & Low \\
\hline Assemblers (electrical and electronic products) & Low \\
\hline Assemblers (vehicles and metal goods) & Low \\
\hline Routine inspectors and testers & Low \\
\hline Weighers, graders and sorters & Low \\
\hline Tyre, exhaust and windscreen fitters & High \\
\hline Sewing machinists & Low \\
\hline Assemblers and routine operatives n.e.c. & Low \\
\hline
\end{tabular}


Occupation

\begin{tabular}{|c|c|}
\hline Scaffolders, stagers and riggers & Low \\
\hline Road construction operatives & Medium \\
\hline Rail construction and maintenance operatives & Medium \\
\hline Construction operatives n.e.c. & Low \\
\hline Large goods vehicle drivers & Low \\
\hline Van drivers & Medium \\
\hline Bus and coach drivers & High \\
\hline Taxi and cab drivers and chauffeurs & High \\
\hline Driving instructors & Medium \\
\hline Crane drivers & Low \\
\hline Fork-lift truck drivers & Low \\
\hline Agricultural machinery drivers & Low \\
\hline Mobile machine drivers and operatives n.e.c. & Low \\
\hline Train and tram drivers & Low \\
\hline Marine and waterways transport operatives & Medium \\
\hline Air transport operatives & High \\
\hline Rail transport operatives & Low \\
\hline Other drivers and transport operatives n.e.c. & Low \\
\hline Farm workers & Low \\
\hline Forestry workers & High \\
\hline Fishing and other elementary agriculture occupations n.e.c. & High \\
\hline Elementary construction occupations & Low \\
\hline Industrial cleaning process occupations & Low \\
\hline Packers, bottlers, canners and fillers & Low \\
\hline Elementary process plant occupations n.e.c. & Low \\
\hline Postal workers, mail sorters, messengers and couriers & High \\
\hline Elementary administration occupations n.e.c. & High \\
\hline
\end{tabular}


Occupation

\begin{tabular}{|c|c|}
\hline Window cleaners & High \\
\hline Street cleaners & High \\
\hline Cleaners and domestics & High \\
\hline Launderers, dry cleaners and pressers & High \\
\hline Refuse and salvage occupations & High \\
\hline Vehicle valeters and cleaners & Low \\
\hline Elementary cleaning occupations n.e.c. & High \\
\hline Security guards and related occupations & High \\
\hline Parking and civil enforcement occupations & High \\
\hline School midday and crossing patrol occupations & High \\
\hline Elementary security occupations n.e.c. & High \\
\hline Shelf fillers & Medium \\
\hline Elementary sales occupations n.e.c. & Medium \\
\hline Elementary storage occupations & Low \\
\hline Hospital porters & High \\
\hline Kitchen and catering assistants & Medium \\
\hline Waiters and waitresses & High \\
\hline Bar staff & High \\
\hline Leisure and theme park attendants & High \\
\hline
\end{tabular}

Other elementary services occupations n.e.c.

Risk level

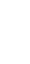


Annex 2: Baseline demand impacts, on the basis of a central scenario, accounting for demand at one metre social distancing, two metre social distancing and whether the job is carried out on a part-time or full-time basis

Social Distance Requirement

Sector

01 Crop and animal production, hunting and related service activities

\begin{tabular}{|c|c|c|c|c|}
\hline Sector & $\mathbf{F T}$ & PT & FT & PT \\
\hline 01 Crop and animal production, hunting and related service activities & $0 \%$ & $0 \%$ & $0 \%$ & $0 \%$ \\
\hline 02 Forestry and logging & $0 \%$ & $0 \%$ & $0 \%$ & $0 \%$ \\
\hline 03 Fishing and aquaculture & $0 \%$ & $0 \%$ & $0 \%$ & $0 \%$ \\
\hline 05 Mining of coal and lignite & $-25 \%$ & $-25 \%$ & $-25 \%$ & $-25 \%$ \\
\hline 06 Extraction of crude petroleum and natural gas & $-25 \%$ & $-25 \%$ & $-25 \%$ & $-25 \%$ \\
\hline 07 Mining of metal ores & $-25 \%$ & $-25 \%$ & $-25 \%$ & $-25 \%$ \\
\hline 08 Other mining and quarrying & $-25 \%$ & $-25 \%$ & $-25 \%$ & $-25 \%$ \\
\hline 09 Mining support service activities & $-25 \%$ & $-25 \%$ & $-25 \%$ & $-25 \%$ \\
\hline 10 Manufacture of food products & $5 \%$ & $10 \%$ & $5 \%$ & $10 \%$ \\
\hline 11 Manufacture of beverages & $5 \%$ & $10 \%$ & $5 \%$ & $10 \%$ \\
\hline 12 Manufacture of tobacco products & $-40 \%$ & $-40 \%$ & $-40 \%$ & $-40 \%$ \\
\hline 13 Manufacture of textiles & $-40 \%$ & $-40 \%$ & $-40 \%$ & $-40 \%$ \\
\hline 14 Manufacture of wearing apparel & $-40 \%$ & $-40 \%$ & $-40 \%$ & $-40 \%$ \\
\hline 15 Manufacture of leather and related products & $-40 \%$ & $-40 \%$ & $-40 \%$ & $-40 \%$ \\
\hline $\begin{array}{c}16 \text { Manufacture of wood and of products of wood and cork, except furniture; } \\
\text { manufacture of articles of straw and plaiting materials }\end{array}$ & $-40 \%$ & $-40 \%$ & $-40 \%$ & $-40 \%$ \\
\hline 17 Manufacture of paper and paper products & $-40 \%$ & $-40 \%$ & $-40 \%$ & $-40 \%$ \\
\hline
\end{tabular}

2-metres

1-metre 


\begin{tabular}{|c|c|c|c|c|}
\hline \multirow[t]{2}{*}{ Social Distance Requirement } & \multicolumn{2}{|c|}{ 2-metres } & \multicolumn{2}{|c|}{ 1-metre } \\
\hline & $\mathbf{F T}$ & PT & FT & PT \\
\hline 18 Printing and reproduction of recorded media & $-40 \%$ & $-40 \%$ & $-40 \%$ & $-40 \%$ \\
\hline 19 Manufacture of coke and refined petroleum products & $-40 \%$ & $-40 \%$ & $-40 \%$ & $-40 \%$ \\
\hline 20 Manufacture of chemicals and chemical products & $-40 \%$ & $-40 \%$ & $-40 \%$ & $-40 \%$ \\
\hline $\begin{array}{l}21 \text { Manufacture of basic pharmaceutical products and pharmaceutical } \\
\text { preparations }\end{array}$ & $-40 \%$ & $-40 \%$ & $-40 \%$ & $-40 \%$ \\
\hline 22 Manufacture of rubber and plastic products & $-40 \%$ & $-40 \%$ & $-40 \%$ & $-40 \%$ \\
\hline 23 Manufacture of other non-metallic mineral products & $-40 \%$ & $-40 \%$ & $-40 \%$ & $-40 \%$ \\
\hline 24 Manufacture of basic metals & $-40 \%$ & $-40 \%$ & $-40 \%$ & $-40 \%$ \\
\hline $\begin{array}{c}25 \text { Manufacture of fabricated metal products, except machinery and } \\
\text { equipment }\end{array}$ & $-40 \%$ & $-40 \%$ & $-40 \%$ & $-40 \%$ \\
\hline 26 Manufacture of computer, electronic and optical products & $-40 \%$ & $-40 \%$ & $-40 \%$ & $-40 \%$ \\
\hline 27 Manufacture of electrical equipment & $-40 \%$ & $-40 \%$ & $-40 \%$ & $-40 \%$ \\
\hline 28 Manufacture of machinery and equipment n.e.c. & $-40 \%$ & $-40 \%$ & $-40 \%$ & $-40 \%$ \\
\hline 29 Manufacture of motor vehicles, trailers and semi-trailers & $-40 \%$ & $-40 \%$ & $-40 \%$ & $-40 \%$ \\
\hline 30 Manufacture of other transport equipment & $-40 \%$ & $-40 \%$ & $-40 \%$ & $-40 \%$ \\
\hline 31 Manufacture of furniture & $-40 \%$ & $-40 \%$ & $-40 \%$ & $-40 \%$ \\
\hline 32 Other manufacturing & $-40 \%$ & $-40 \%$ & $-40 \%$ & $-40 \%$ \\
\hline 33 Repair and installation of machinery and equipment & $-40 \%$ & $-40 \%$ & $-40 \%$ & $-40 \%$ \\
\hline 35 Electricity, gas, steam and air conditioning supply & $-5 \%$ & $-5 \%$ & $-5 \%$ & $-5 \%$ \\
\hline 36 Water collection, treatment and supply & $-5 \%$ & $-5 \%$ & $-5 \%$ & $-5 \%$ \\
\hline 37 Sewerage & $-5 \%$ & $-5 \%$ & $-5 \%$ & $-5 \%$ \\
\hline
\end{tabular}




\begin{tabular}{|c|c|c|c|c|}
\hline \multirow[t]{2}{*}{ Social Distance Requirement } & \multicolumn{2}{|c|}{ 2-metres } & \multicolumn{2}{|c|}{ 1-metre } \\
\hline & $\mathbf{F T}$ & PT & $\mathbf{F T}$ & PT \\
\hline 38 Waste collection, treatment and disposal activities; materials recovery & $-5 \%$ & $-5 \%$ & $-5 \%$ & $-5 \%$ \\
\hline 39 Remediation activities and other waste management services & $-5 \%$ & $-5 \%$ & $-5 \%$ & $-5 \%$ \\
\hline 41 Construction of buildings & $-30 \%$ & $-50 \%$ & $-30 \%$ & $-50 \%$ \\
\hline 42 Civil engineering & $-30 \%$ & $-50 \%$ & $-30 \%$ & $-50 \%$ \\
\hline 43 Specialised construction activities & $-30 \%$ & $-50 \%$ & $-30 \%$ & $-50 \%$ \\
\hline 45 Wholesale and retail trade and repair of motor vehicles and motorcycles & $-50 \%$ & $-50 \%$ & $-50 \%$ & $-50 \%$ \\
\hline 46 Wholesale trade, except of motor vehicles and motorcycles & $-50 \%$ & $-50 \%$ & $-50 \%$ & $-50 \%$ \\
\hline 47 Retail trade, except of motor vehicles and motorcycles & $-50 \%$ & $-50 \%$ & $-50 \%$ & $-50 \%$ \\
\hline 48 Wholesale and retail n.o.s. & $-50 \%$ & $-50 \%$ & $-50 \%$ & $-50 \%$ \\
\hline 49 Land transport and transport via pipelines & $-18 \%$ & $-18 \%$ & $-18 \%$ & $-18 \%$ \\
\hline 50 Water transport & $-18 \%$ & $-18 \%$ & $-18 \%$ & $-18 \%$ \\
\hline 51 Air transport & $-18 \%$ & $-18 \%$ & $-18 \%$ & $-18 \%$ \\
\hline 52 Warehousing and support activities for transportation & $-18 \%$ & $-18 \%$ & $-18 \%$ & $-18 \%$ \\
\hline 53 Postal and courier activities & $-18 \%$ & $-18 \%$ & $-18 \%$ & $-18 \%$ \\
\hline 55 Accommodation & $-66 \%$ & $-80 \%$ & $-40 \%$ & $-48 \%$ \\
\hline 56 Food and beverage service activities & $-66 \%$ & $-80 \%$ & $-40 \%$ & $-48 \%$ \\
\hline 58 Publishing activities & $-20 \%$ & $-20 \%$ & $-12 \%$ & $-12 \%$ \\
\hline $\begin{array}{l}59 \text { Motion picture, video and television programme production, sound } \\
\text { recording and music publishing activities }\end{array}$ & $-20 \%$ & $-20 \%$ & $-12 \%$ & $-12 \%$ \\
\hline 60 Programming and broadcasting activities & $-20 \%$ & $-40 \%$ & $-20 \%$ & $-40 \%$ \\
\hline
\end{tabular}




\begin{tabular}{|c|c|c|c|c|}
\hline \multirow[t]{2}{*}{ Social Distance Requirement } & \multicolumn{2}{|c|}{ 2-metres } & \multicolumn{2}{|c|}{ 1-metre } \\
\hline & FT & PT & FT & PT \\
\hline 61 Telecommunications & $-20 \%$ & $-20 \%$ & $-20 \%$ & $-20 \%$ \\
\hline 62 Computer programming, consultancy and related activities & $-20 \%$ & $-20 \%$ & $-20 \%$ & $-20 \%$ \\
\hline 63 Information service activities & $-20 \%$ & $-20 \%$ & $-20 \%$ & $-20 \%$ \\
\hline 64 Financial service activities, except insurance and pension funding & $-5 \%$ & $-5 \%$ & $-5 \%$ & $-5 \%$ \\
\hline $\begin{array}{c}65 \text { Insurance, reinsurance and pension funding, except compulsory social } \\
\text { security }\end{array}$ & $-5 \%$ & $-5 \%$ & $-5 \%$ & $-5 \%$ \\
\hline 66 Activities auxiliary to financial services and insurance activities & $-5 \%$ & $-5 \%$ & $-5 \%$ & $-5 \%$ \\
\hline 68 Real estate activities & $-40 \%$ & $-40 \%$ & $-40 \%$ & $-40 \%$ \\
\hline 69 Legal and accounting activities & $-10 \%$ & $-10 \%$ & $-10 \%$ & $-10 \%$ \\
\hline 70 Activities of head offices; management consultancy activities & $-10 \%$ & $-10 \%$ & $-10 \%$ & $-10 \%$ \\
\hline 71 Architectural and engineering activities; technical testing and analysis & $-10 \%$ & $-10 \%$ & $-10 \%$ & $-10 \%$ \\
\hline 72 Scientific research and development & $-10 \%$ & $-10 \%$ & $-10 \%$ & $-10 \%$ \\
\hline 73 Advertising and market research & $-10 \%$ & $-10 \%$ & $-10 \%$ & $-10 \%$ \\
\hline 74 Other professional; scientific and technical activities & $-10 \%$ & $-10 \%$ & $-10 \%$ & $-10 \%$ \\
\hline 75 Veterinary activities & $-10 \%$ & $-10 \%$ & $-10 \%$ & $-10 \%$ \\
\hline 77 Rental and leasing activities & $-20 \%$ & $-40 \%$ & $-20 \%$ & $-40 \%$ \\
\hline 78 Employment activities & $-20 \%$ & $-40 \%$ & $-20 \%$ & $-40 \%$ \\
\hline $\begin{array}{l}79 \text { Travel agency, tour operator and other reservation service and related } \\
\text { activities }\end{array}$ & $-20 \%$ & $-40 \%$ & $-20 \%$ & $-40 \%$ \\
\hline 80 Security and investigation activities & $-20 \%$ & $-20 \%$ & $-20 \%$ & $-20 \%$ \\
\hline 81 Services to buildings and landscape activities & $-20 \%$ & $-20 \%$ & $-20 \%$ & $-20 \%$ \\
\hline
\end{tabular}




\begin{tabular}{|c|c|c|c|c|}
\hline \multirow[t]{2}{*}{ Social Distance Requirement } & \multicolumn{2}{|c|}{ 2-metres } & \multicolumn{2}{|c|}{ 1-metre } \\
\hline & FT & PT & FT & PT \\
\hline 82 Office administrative, office support and other business support activities & $-20 \%$ & $-40 \%$ & $-20 \%$ & $-40 \%$ \\
\hline 84 Public administration and defence; compulsory social security & $0 \%$ & $0 \%$ & $0 \%$ & $0 \%$ \\
\hline 85 Education & $-5 \%$ & $-5 \%$ & $-5 \%$ & $-5 \%$ \\
\hline 86 Human health activities & $10 \%$ & $15 \%$ & $10 \%$ & $15 \%$ \\
\hline 87 Residential care activities & $10 \%$ & $15 \%$ & $10 \%$ & $15 \%$ \\
\hline 88 Social work activities without accommodation & $10 \%$ & $15 \%$ & $10 \%$ & $15 \%$ \\
\hline 90 Creative, arts and entertainment activities & $-45 \%$ & $-45 \%$ & $-27 \%$ & $-27 \%$ \\
\hline 91 Libraries, archives, museums and other cultural activities & $-45 \%$ & $-45 \%$ & $-27 \%$ & $-27 \%$ \\
\hline 92 Gambling and betting activities & $-45 \%$ & $-45 \%$ & $-27 \%$ & $-27 \%$ \\
\hline 93 Sports activities and amusement and recreation activities & $-45 \%$ & $-45 \%$ & $-27 \%$ & $-27 \%$ \\
\hline 94 Activities of membership organisations & $-40 \%$ & $-40 \%$ & $-24 \%$ & $-24 \%$ \\
\hline 95 Repair of computers and personal and household goods & $-40 \%$ & $-40 \%$ & $-24 \%$ & $-24 \%$ \\
\hline 96 Other personal service activities & $-40 \%$ & $-40 \%$ & $-24 \%$ & $-24 \%$ \\
\hline 97 Activities of households as employers of domestic personnel & $-50 \%$ & $-50 \%$ & $-30 \%$ & $-30 \%$ \\
\hline $\begin{array}{c}98 \text { Undifferentiated goods- and services-producing activities of private } \\
\text { households for own use }\end{array}$ & $-50 \%$ & $-50 \%$ & $-30 \%$ & $-30 \%$ \\
\hline 99 Activities of extraterritorial organisations and bodies & $-30 \%$ & $-30 \%$ & $-18 \%$ & $-18 \%$ \\
\hline
\end{tabular}




\section{Author Biographies}

Richard Johnston is an Economist in Ulster University with more than twenty years of experience working in the public, private, academic and third sector. He is a member of Northern Ireland's Ministerial Economic Advisory Group, was a member of the Ministerial Advisory Panel on Infrastructure and serves on the Board of Warrenpoint Harbour and Inspire Business Centre.

Ryan Hogg has worked as a research economist for four years, focusing on the UK regional economies and the Northern Ireland labour market. He ran the Ulster University Economic Policy Centre forecasting model and during his time there has worked on projects allied to the COVID-19 pandemic. He studied Economics at the University of Glasgow, and now works as a freelance journalist and economic researcher, with an interest in skills and socioeconomic policy

Dr Kristel Miller is a Reader in Innovation and Strategy at Ulster University. Her expertise is in business models, innovation management, university-industry knowledge transfer, technology commercialization and competitiveness. She has published in many high-quality international journals. Kristel an expert adviser and reviewer for the European Commission and the Economic and Social Research Council. Kristel also works with organisations to help them develop their innovation capabilities and grow. 